\title{
DICE-RD: an implementation of rate-related damages in the DICE model
}

\author{
Peter Michaelis ${ }^{1} \cdot$ Heiko Wirths ${ }^{2}$
}

Received: 4 February 2019 / Accepted: 11 February 2020 / Published online: 28 February 2020

(C) The Author(s) 2020

\begin{abstract}
A growing body of literature from the natural and the social sciences indicates that the rate of temperature increase is another key driver of total climate damages, next to the absolute increase in temperature compared to the pre-industrial level. Nonetheless, the damage functions employed in integrated assessment models that aim at studying the economics of climate change usually are based solely on the absolute temperature increase. Hence, these models neglect additional damages that will occur if the rate of temperature increase exceeds a certain threshold that overstrains the adaptive capacities of ecological and social systems. In the present paper, we implement such rate-related damages in the well-known integrated assessment model DICE-2016R. Using the resulting model variant DICE-RD, we show for several scenarios that an insufficient climate policy that ignores rate-related damages can lead to substantial economic losses.
\end{abstract}

Keywords Integrated assessment $\cdot$ DICE model $\cdot$ Climate policy $\cdot$ Rate of temperature increase

JEL Classification O44 · Q54 · Q58

\section{Introduction}

Studying the economics of climate change, economists often use so-called integrated assessment models (IAMs) that combine the framework of a neoclassical growth model with a climate module. The major subject of study is the economically

Peter Michaelis

peter.michaelis@wiwi.uni-augsburg.de

Heiko Wirths

heikowirths@yahoo.de

1 Faculty of Business and Economics, University of Augsburg, Augsburg, Germany

2 Amprion $\mathrm{GmbH}$, Dortmund, Germany 
optimal emission mitigation path, which accounts for mitigation costs on the one hand and climate damage costs on the other. The latter are represented by a damage function that describes the economic impacts of climate change. Typically, these damage functions are based solely on the absolute temperature increase compared to the pre-industrial level, but not on the rate of temperature increase, i.e., the increase in temperature that occurs per decade.

However, as stressed several times in the IPCC's Fifth Assessment Report (see IPCC 2014a), and as underlined by a growing body of literature from the natural and - to a smaller extent-from the social sciences, the rate of temperature increase is also an important driver of overall damages caused by climate change (see Sect. 2). ${ }^{1}$ Consequently, neglecting such rate-related damages can lead to suboptimal emission mitigation caused by an underestimation of damages.

This paper incorporates rate-related damages into the well-known DICE-2016R model by William Nordhaus (2018). Using the resulting model variant DICE-RD, we analyze the potential welfare effects caused by the rate of temperature increase for several scenarios. Each scenario compares the net output stemming from the optimal climate policy with the net output resulting from the reference policy that ignores rate-related damages. The differences in net output then can be interpreted as the economic losses that occur if rate-related damages are neglected.

The present paper proceeds as follows. Section 2 illustrates the importance of rate-related damages by several examples from the literature. In Sect. 3, we justify the use of DICE-2016R, summarize the main criticisms of this model and compare it to other IAMs with special reference to the integration of rate-related damages. In Sect. 4, we shortly outline those parts of DICE-2016R that are important for our analysis, and in Sect. 5, we incorporate rate-related damages into the model. In Sect. 6, we discuss the results of our base scenario, and in Sect. 7, we present a comprehensive sensitivity analysis. In Sect. 8, we consider the case of a fixed temperature target, and in Sect. 9, we summarize our findings and highlight the need for further research.

\section{Impacts of the rate of temperature increase}

The harmful impacts caused by a high rate of temperature increase are best understood in the field of ecosystems and biodiversity (for an overview of studies, see Warren et al. 2011). Several species of flora and fauna are endangered by displacement or even complete extinction when the temperature increases faster than they are able to adapt (e.g., Neilson et al. 2005, O'Neill et al. 2017, Millington et al. 2019). This adaptation might be a migration to new habitats with more suitable conditions, ${ }^{2}$ or a change in the distribution of phenotypes within a given species toward

\footnotetext{
1 See Tahvonen (1995) for an early analytical treatment of the implications for optimal mitigation with a short empirical application based on a modified static precursor of the DICE model (Nordhaus 1991).

2 I.e., moving pole-wards or moving to higher altitudes in case of increasing temperatures (e.g., Loarie et al. 2009). However, as Malcolm et al. (2002) point out, the current rates of temperature increase require migration rates that are much faster than those observed during the complete postglacial period.
} 
the better-adapted ones (e.g., Visser 2008, Corlett and Westcott 2013, Christmas et al. 2016). The capability of species to adapt by migration or genetic evolution, however, naturally depends on how fast the climate is changing. Hence, rates of temperature increase that exceed a certain threshold will reduce biodiversity by selecting highly mobile or opportunistic species (Malcolm et al. 2002).

In particular, according to Leemans and Eickhout (2004), the adaptive capacity of forest ecosystems is much lower than the one of other ecosystems. ${ }^{3}$ This is of considerable importance for the future trend of climate change, since the decomposition processes associated with a large-scale dieback of forests could lead to huge releases of $\mathrm{CO}_{2}$ from the terrestrial biosphere, thereby producing a significant feedback mechanism that accelerates global warming (e.g., Neilson 1993, Kirschbaum 2000, Cox et al. 2004, Bhatti et al. 2012, Price et al. 2013).

Acceptable thresholds for the rate of temperature increase, where the adaptive capacity of most species and ecosystems can cope with climate change, have been studied for almost 30 years. Early estimates suggest a "tolerable window" of not more than $0.1{ }^{\circ} \mathrm{C}$ per decade (Vellinga and Swart 1991). More recent studies come to similar conclusions ranging from $0.05{ }^{\circ} \mathrm{C}$ per decade (van Vliet and Leemans 2006) to $0.2^{\circ} \mathrm{C}$ per decade (Petschel-Held et al. 1999; Leemans and Eickhout 2004). In contrast, assuming "business as usual" conditions, Nordhaus (2018) calculates a temperature trajectory that implies a peak level of almost $0.4{ }^{\circ} \mathrm{C}$ per decade around the middle of this century (for details see Sect. 5).

Besides ecosystems and biodiversity, the rate of temperature increase has impacts on several direct economic activities. The most obvious one is agriculture, which heavily depends on ecosystem services that are partially endangered if temperature rises too fast. ${ }^{4}$ Moreover, global warming requires the adaptation of agricultural practices to changing environmental conditions. This requires not only short-term measures like the switch to crops with higher resistance to heat shocks and drought, but also the long-term building of appropriate institutions and infrastructure that enhance adaptive capacity in the agricultural sector (e.g., Lobell et al. 2008, Rickards and Howden 2012). However, the faster the climate change occurs, the less likely it is that these measures can be established in time..$^{5}$

In forestry, the impacts of the rate of temperature increase are evident regarding commercially used tree species. These are affected by climate change, because suitable regions move pole-wards due to global warming. When the rate of temperature increase is too fast, the species' population will decline on the whole because the natural rate of migration to suitable regions cannot cope with the pace of climate change. Consequently, in forestry, proper migration to new habitats needs to be commercially assisted (Zhu et al. 2012; Pedlar et al. 2012). According to Howden et al.

\footnotetext{
${ }^{3}$ E.g., at a rate of temperature increase of $0.3{ }^{\circ} \mathrm{C}$ per decade, $30 \%$ of all impacted ecosystems are still able to adapt within a century, but only $17 \%$ of all impacted forests (Leemans and Eickhout 2004).

4 These services include, among others, pollination and nutrient cycling. On their importance for agriculture, see, e.g., Zhang et al. 2007, Brady et al. 2015 and Bommarco et al. 2017.

5 Due to low adaptive capacities, these problems are particularly virulent in developing countries and in the subsistence farming sector (e.g., Bellon et al. 2011, Tambo and Aboulaye 2012, 2013).
} 
(2007), a closely related problem is the long time lags between planting and harvesting, which makes it difficult to adapt properly to rapidly rising temperatures. As a consequence, timber companies might be forced to a premature harvest of trees that are no longer able to keep up with the changed climatic conditions (Mendelsohn 2000).

Moreover, although specific literature on this topic is still scarce, several other sectors are potentially affected by the rate of temperature increase. As emphasized by Mendelsohn (2000), sectors that are burdened with long-lived capital which cannot readily be fitted to changing climate conditions are particularly vulnerable, since they might be forced to depreciate capital more rapidly than normal. An example might be the premature close-down of a hydroelectric power station due to water shortage. In addition, the adaptation of human systems to climate change often presupposes huge time-consuming investments in knowledge, institutions and infrastructure that "can take decades" as stressed by Patt et al. (2010, p. 392). ${ }^{6}$ Prominent examples are adaptive investments in the fields of coastal protection (e.g., Shayegh et al. 2016) and the development of new vaccines and vaccination schemes against infectious diseases that spread faster as temperatures rise (e.g., Kurane 2010). A high rate of temperature increase entails the danger that these measures cannot keep up with the speed of warming. ${ }^{7}$

Another issue within the present context are so-called "tipping points" where climatic conditions change abruptly, irreversibly and in a hardly predictable manner. Examples are the shutoff of the thermohaline circulation (e.g., Latif et al. 2006) or the collapse of the Indian summer monsoon (e.g., Zickfeld et al. 2005). According to Lenton et al. (2008) and Lenton (2011), the risks of passing such tipping points can directly be attributed to the rate of temperature increase. However, the issue of tipping points will be neglected in the following analysis, because the rates of temperature increase that entail the danger of passing a tipping point are far above those that cause the problems discussed in the present section.

\section{The use of DICE-2016R for analyzing the impacts of rate-related damages}

The damage function of DICE-2016R, as well as those of most other IAMs, relies exclusively on the absolute level of temperature increase. However, as substantiated in the last section, the rate of temperature increase is an important driver of damages as well. When the first generation of IAMs came up in the early 1990s, this issue had been discussed, but with the exceptions described below, the damage functions employed in IAMs do not account for rate-related damages.

\footnotetext{
${ }^{6}$ For a detailed overview of adaptation measures and the barriers to them see IPCC (2014a, Chapter 16).

7 According to the IPCC (2014b, chapter 28), this problem is particularly pressing in the Polar regions where the rate of temperature increase is about twice as high as the global average (see also Overland et al. 2013).
} 
The earliest exception traces back to the work of Peck and Teisberg (1994). The authors compare the results of their original CETA model, where damages are driven by the absolute level of temperature, with those of a modified version where damages depend on the rate of temperature increase. Their main finding is that optimal mitigation rates rather hinge on the shape of the damage function (e.g., quadratic or cubic) than on the question whether the absolute level or the rate of temperature increase is considered. The modified damage function used by Peck and Teisberg (1994), however, does not account for both variables at the same time. Consequently, the authors do not analyze the joint effects of both damage categories. Moreover, today the CETA model, which dates back to the early 1990s, is outdated in its parameterization.

Another IAM that partially accounts for rate-related damages is the FUND model (Tol 1997; Tol and Anthoff 2014). In this approach, however, only the impacts on agriculture depend on the absolute level as well as on the rate of temperature increase, whereas the impacts on all other sectors are modeled in the conventional way. Moreover, FUND exhibits only a limited degree of endogeneity, since production activities and the resulting emissions follow exogenous trajectories. Consequently, in contrast to DICE, it is not possible to derive a complete first-best solution including the optimal level of production.

Also, the PAGE model (Hope 2006, 2013) accounts to some extent for raterelated damages. This model, however, is a probabilistic simulation model that mainly serves to analyze the impacts of uncertainty. The degree of endogeneity is even lower than in FUND, because not only production but also mitigation rates are exogenous. Hence, within PAGE it is not possible to investigate the impact of raterelated damages on optimal climate policies. ${ }^{8}$

The most recent contribution is the work of Goes et al. (2011) who analyze the effects of aerosol geoengineering within the DICE-2007 model. Since the injection of aerosols into the atmosphere can lead to very fast changes in temperature, the authors use a modified damage function based on the rate of temperature increase in terms of 5-year and 30-year running averages. However, the focus of Goes et al. (2011) is solely on the effects of geoengineering. Their general approach as well as their damage function is not designed to investigate the role of rate-related damages in determining optimal climate policies.

Besides the small-scale IAMs described so far, there exists a whole range of more complex large-scale IAMs used by, e.g., the IPCC to simulate alternative emission pathways that aim at limiting the increase in global mean temperature to a certain degree (IPCC 2014c). ${ }^{9}$ These models usually combine a detailed representation of the energy sector with an extensive model of the global carbon cycle that translates the emissions from the energy system into the resulting temperature change.

\footnotetext{
${ }^{8}$ For a more thorough comparison between DICE, FUND and PAGE, see, e.g., Mastrandrea (2009), Stanton et al. (2009) and van Vuuren et al. (2011a).

9 According to IPCC (1996), these models can also be classified as policy-evaluation models (in contrast to policy-optimization models). Examples of the most widely used large-scale IAMs are IMAGE (Stehfest et al. 2014), AIM/CGE (Fujimori et al. 2012) and MESSAGE (Krey et al. 2016). For a critical overview see, e.g., Wilson et al. (2017) or Gambhir et al. (2019).
} 
However, in contrast to small-scale IAMs, impacts on the economy caused by climate change are largely neglected (e.g., Nordhaus and Sztorc 2013, IPCC, 2014b, Farmer et al. 2015). As far as large-scale IAMs consider climate impacts at all, they are limited to single sectors such as, e.g., agriculture or water supply (for an overview, see Weyant 2017, pp. 120-121). Hence, due to an incomplete coverage of impacts, large-scale IAMs are not well suited to analyze the overall economic effects of rate-related damages. Moreover, the rate of temperature increase is considered in these models only to the extent that some of them have been used to analyze how mitigation costs change if not only the absolute increase in temperature, but also its rate is to be limited (e.g., Toth et al. 2003, Böhringer et al. 2006).

To our best knowledge, the DICE model is the most appropriate approach for the topic of our paper. Since the development of the first version (Nordhaus 1994), DICE has probably become the most popular small-scale IAM in the economics of climate change. In the "business as usual" scenario of DICE-2016R that relies on an indefinite extension of climate policies as of 2010, the resulting temperature trajectory is essentially consistent with the RCP 8.5 -scenario derived by the IPCC from a set of large-scale IAMs (Nordhaus 2018). ${ }^{10}$ Moreover, the code of the model is publicly available, ${ }^{11}$ and due to its comparatively simple structure, it offers a high degree of transparency, whereas the more complex large-scale IAMs partially can be viewed as "black box" models (Gambhir et al. 2019). Finally, due to its popularity, DICE entails the advantage that our results are comparable with those of many other studies using the same model family.

Of course, we are aware of the harsh criticisms in the literature on the DICE model and partially also on IAMs in general. ${ }^{12}$ At the heart of these criticisms is often the damage function which has huge effects on the results, and at the same time can be considered as the "most speculative element of the analysis" (Pindyck 2013, p. 862). Within this context, some of the most critical issues relate to uncertainty often coupled with tipping points and potential catastrophes (e.g., Stern 2013, Burke et al. 2015a, 2018), as well as to the insufficient treatment of non-market impacts. The latter range from well-studied effects like ecosystem damages ${ }^{13}$ to less-known

\footnotetext{
${ }_{10}$ The abbreviation RCP refers to the four Representative Concentration Pathways (RCP2.6, RCP4.5, RCP6, RCP8.5) used by, e.g., the IPPC for modeling climate change. The pathway RCP 8.5 describes the likely outcome of a "business as usual" scenario where radiative forcing is estimated to increases up to $8.5 \mathrm{Watt} / \mathrm{m}^{2}$ by the year 2100 (e.g., van Vuuren et al. 2011b).

${ }^{11}$ The source code of DICE-2016R can be downloaded at https://www.econ.yale.edu/ nordhaus/homep age/homepage/DICE2016R-091916ap.gms. Last access at 30/01/2020.

${ }^{12}$ Due to limited space, we can only provide a cursory and incomplete summary. For a thorough discussion see the literature cited above as well as Ackerman et al. (2009), Stanton et al. (2009), Howard and Sterner (2017), Pindyck (2017), NASEM (2017) and Weyant (2017).

${ }^{13}$ Note that in the DICE model, all damages are measured as losses in GDP. Concerning ecosystem damages (which are of particular importance for our study), this approach might seem odd, since ecosystem damages regularly do not show up directly in the GDP. However, there are many instances where these damages indirectly reduce the GDP. For example, coastal degradation can amplify the damages caused by flooding and the extinction of insects can affect the productivity in agriculture (for a comprehensive overview see IPCC 2014a).
} 
areas like the linkage between climate change and increasing human conflicts (e.g., Hsiang and Burke 2014, Burke et al. 2015b).

A critical issue upstream of the damage function is the veil of uncertainty surrounding the "climate sensitivity" which constitutes the link between the atmospheric $\mathrm{CO}_{2}$ concentration and the accompanying increase in global mean temperature (e.g., Weitzman 2011). ${ }^{14}$ Further controversially discussed issues relate to the crucial role of discounting (e.g., Stern 2007, Dasgupta 2008, Goulder and Williams 2012, Arrow et al. 2014, Heal and Millner 2014) and to the maximization of a single global welfare function that omits considerations of regional equity in particular with respect to developing countries (e.g., Stanton and Ackerman 2009).

Finally, several criticisms relate to technological aspects. For example, despite the well-known insights from the literature on endogenous technological change (Romer 1990), in the DICE model technical progress with respect to the total factor productivity, to mitigation costs and to the decarbonization of production follows exogenously given trends in time (e.g., Farmer et al. 2015). Moreover, as pointed out by Grubb et al. (2014, p. 496), the mitigation cost function "involves no history" as "the cost of cutting emissions in 2010, for example, is wholly unaffected by anything that happens before". In practice, however, emissions mitigation requires a restructuring of the capital stock such that a sharp increase in mitigation rates between two periods would involve extra costs for, e.g., the premature replacement of power plants. Due to these and other limitations of the DICE model, the results derived in the following sections can at best be considered as rough estimates and must be interpreted with caution.

\section{The DICE-2016R model}

In the following, we describe only those parts of the DICE-2016R model that are important for our analysis. ${ }^{15}$ Utility is expressed by a standard constant-relative-riskaversion utility function:

$$
U[c(t), L(t)]=L(t)\left[\frac{c(t)^{1-\alpha}}{1-\alpha}\right] .
$$

The time index $t$ indicates the specific period, $c(t)$ is per capita consumption, $L(t)$ is the population and $\alpha$ is the elasticity of marginal utility of consumption which is set at 1.45 . The objective function to be maximized is the welfare function $\mathrm{W}$. The latter consists of the discounted utility summed up over a finite time horizon of 100 periods each covering 5 years:

\footnotetext{
14 At the benchmark of a doubled $\mathrm{CO}_{2}$ concentration compared to pre-industrial levels, DICE-2016R assumes an increase in temperature of $3.1^{\circ} \mathrm{C}$, whereas the IPCC (2013) estimates a likely range of $1.5^{\circ} \mathrm{C}$ to $4.5^{\circ}$, but larger magnitudes up to $6{ }^{\circ} \mathrm{C}$ can also not be ruled out completely.

15 For more details on DICE-2016R, see Nordhaus (2018). A thorough description of the almost identical model DICE-2013R is provided by Nordhaus and Sztorc (2013).
} 


$$
W[c(t), L(t)]=\sum_{t=1}^{T} \frac{1}{(1+\rho)^{t-1}} U[c(t), L(t)] .
$$

The parameter $\rho$ indicates the pure rate of social time preference, which is set at $1.5 \%$. The production function is of Cobb-Douglas type $Y(t)=A(t) K(t)^{\gamma} L(t)^{1-\gamma}$ with $Y(t)$ indicating gross output. $A(t)$ is the total factor productivity, $K(t)$ is the capital stock and $L(t)$ is not only the population but also the labor input and $\gamma$ is the elasticity of output with respect to the capital.

The link to the climate module is formed via greenhouse gas emissions $E(t)$ that are composed of industrial emissions and exogenously given emissions resulting from non-industrial activities (e.g., land use changes) denoted by $E_{\text {Land }}(t)$. Industrial emissions are caused by production due to an exogenous emission coefficient $\sigma(t)$ which declines over time. The share $\mu(t)$ of these emissions is avoided by mitigation activities such that total emissions are given by:

$$
E(t)=[1-\mu(t)] \sigma(t) Y(t)+E_{\text {Land }}(t) .
$$

The accumulation of emissions leads to a higher atmospheric greenhouse gas concentration that causes an increase in radiative forcing. In the next step, the increased radiative forcing triggers a higher level of temperature. The economic impact of this temperature increase is given by a quadratic damage function $D(t)$, which describes the share of output lost due to climate damages:

$$
D(t)=\psi_{1} \cdot T_{\mathrm{AT}}(t)+\psi_{2} \cdot T_{\mathrm{AT}}(t)^{2} .
$$

$T_{\mathrm{AT}}(t)$ indicates the increase in the global atmospheric mean temperature compared to the pre-industrial level, and the parameters $\psi_{i}(i=1,2)$ determine the shape of the damage function.

With respect to (4), the question might arise whether the function $D\left[T_{\mathrm{AT}}(t)\right]$ does not already take into account rate-related damages. Of course, any absolute temperature increase $T_{\mathrm{AT}}(t)$ can be decomposed into a sequence of rates of temperature increase: $T_{\mathrm{AT}}(t)=T_{\mathrm{AT}}(0)+\sum_{\tau=1}^{t} \Delta T_{\mathrm{AT}}(\tau)$ with $\Delta T_{\mathrm{AT}}(t):=T_{\mathrm{AT}}(t)-T_{\mathrm{AT}}(t-1)$. In this sense, it could be argued that (4) already considers the changes in temperature that occurred between two successive periods. However, there is no explicit consideration of the additional damages caused by the current rate of temperature increase. For example, a temperature compared to pre-industrial levels of $T_{\mathrm{AT}}(t)=1.2$ leads to the same damage in period $t$, regardless of whether the temperature in the previous period $t-1$ was, say, $T_{\mathrm{AT}}(t-1)=1.1$ or $T_{\mathrm{AT}}(t-1)=0.8$.

Next, the mitigation cost function $\Lambda(t)$ is defined in terms of the share of output spent for mitigation activities:

$$
\Lambda(t)=\theta_{1} \cdot \mu(t)^{\theta_{2}} .
$$

The variable $\mu(t)$ indicates the mitigation rate (i.e., the share of emissions avoided), and the parameters $\theta_{i}(i=1,2)$ determine the shape of the mitigation cost function. 
Subtracting damages and mitigation costs from the gross output $Y(t)$ yields the remaining net output $Y_{n e t}(t)=[1-D(t)-\Lambda(t)] Y(t)$ to be divided into consumption and investment. The latter equation highlights the typical trade-off in climate policies: emission mitigation leads to mitigation costs $\Lambda(t)$ resulting in a decreasing net output. However, at the same time, emission mitigation reduces damages $D(t)$ resulting in an increasing net output. To solve the model, the mitigation rates $\mu(t)$ and the division of net output between consumption $C(t)$ and investments $I(t)$ are determined in such a way that the objective function (2) is maximized.

Finally, it should be noted that the maximization approach underlying the DICE model implicitly assumes the existence of a benevolent social planner who is able to calculate and enforce the optimal climate policy. Within a competitive market economy, however, the optimum could be decentralized by introducing a harmonized global carbon tax that equals the social cost of carbon calculated along the optimal emission pathway. ${ }^{16}$ Although such a scenario of global cooperation is far from reality, it provides a useful efficiency benchmark for evaluating more realistic policy options (Nordhaus and Sztorc 2013).

\section{From DICE-2016R to DICE-RD}

To transform DICE-2016R into DICE-RD, we have to modify the damage function (4). The new function should incorporate the absolute level as well as the rate of temperature increase as a driver of damages. Moreover, it should account for the threshold dependency of rate-related damages. Both requirements can be satisfied via replacing the original damage function $\mathrm{D}(\mathrm{t})$ by the new damage function $Z(t)$ :

$$
Z(t):=\left[\psi_{1} \cdot T_{\mathrm{AT}}(t)+\psi_{2} \cdot T_{\mathrm{AT}}(t)^{2}\right] \cdot \delta(t) .
$$

The term in square brackets on the RHS of (6) represents the original damage function $D(t)$ and the multiplier $\delta(t) \geq 1$ accounts for the effect of rate-related damages. ${ }^{17}$ The latter depend on the rate of temperature increase defined as $\Delta T_{\mathrm{AT}}(t):=T_{\mathrm{AT}}(t)-T_{\mathrm{AT}}(t-1)$ :

$$
\delta(t):=1+B(t) \cdot \frac{\lambda}{100} \cdot\left[\frac{\Delta T_{\mathrm{AT}}(t)-0.5 v}{0.5 v}\right]^{\omega} .
$$

The parameters $\lambda$ and $\omega$ govern the shape of the multiplier function $\delta(t)$, and $v$ indicates the critical threshold for the rate of temperature increase measured in ${ }^{\circ} \mathrm{C}$ per decade. Since each period of DICE-2016R covers only 5 years, we have to use an internal threshold of $0.5 v$ in our model. The damage parameter $\lambda$ is calibrated in

\footnotetext{
16 The social cost of carbon measure "the present value of additional economic damages now and in the future caused by an additional ton of carbon emissions" (Nordhaus 2008, p. 11).

17 We assume a multiplicative instead of an additive relationship between both types of damages, because systems that are already disturbed by the absolute level of temperature increase will probably have more problems coping with the additional stress caused by a high rate of temperature increase.
} 


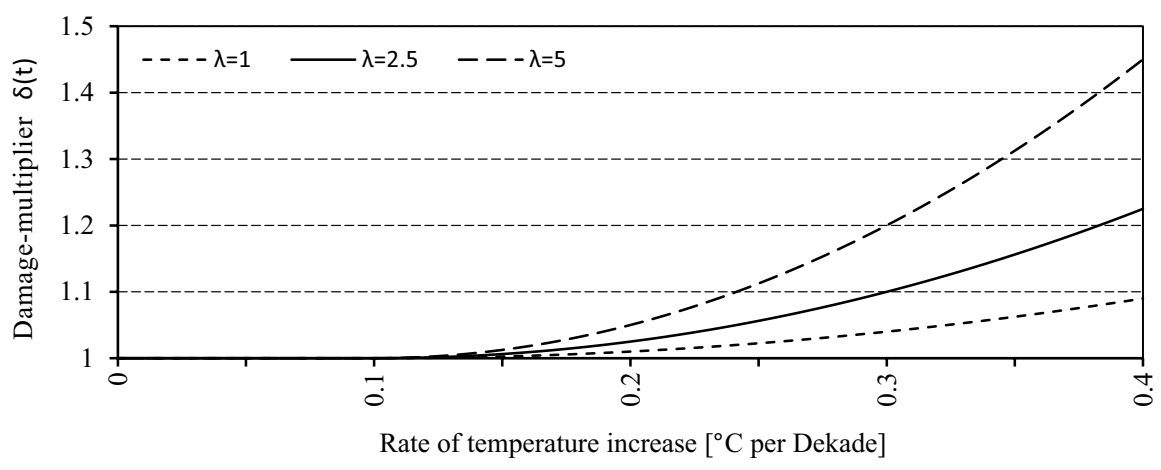

Fig. 1 Shape of the damage multiplier $\delta(t)$ for an example with $v=0.1, \omega=2$ and varying magnitudes of the parameter $\lambda$

such a way that it indicates the percentage increase in total damages if the increase in temperature between two periods is twice as high as the internal threshold, i.e., $\Delta T_{\mathrm{AT}}(t)=v$. Moreover, according to the binary variable $B(t)$ defined below in (8), rate-related damages only occur if the rate of temperature increase between two periods exceeds the internal threshold of $0.5 \mathrm{v}$. Otherwise, we obtain a multiplier of $\delta(t)=1$ and the new damage function $Z(t)$ equals the original one $\mathrm{D}(\mathrm{t})$ :

$$
B(t):=\left\{\begin{array}{lll}
0 & \text { if } & \Delta T_{\mathrm{AT}}(t) \leq 0.5 v \\
1 & \text { if } \quad \Delta T_{\mathrm{AT}}(t)>0.5 v
\end{array} .\right.
$$

As an example, Fig. 1 illustrates the shape of the damage multiplier $\delta(t)$ for the case of $v=0.1, \omega=2$ and varying magnitudes of the parameter $\lambda$. $^{18}$

In our base scenario in Sect. 6, we employ the best guess threshold of $0.1{ }^{\circ} \mathrm{C}$ per decade, i.e., $v=0.1$. In contrast to this more or less reliable figure (see Sect. 2), the range of the parameters $\lambda$ and $\omega$ is almost completely uncertain. At the present state of insights from the social and natural sciences, we can only conclude that $\lambda$ should be strictly positive, and $\omega$ should be larger than one, since rate-related damages are expected to increase more than proportionately when the rate of temperature increase becomes larger (e.g., Leemans and Eickhout 2004). Our base scenario assumes a quadratic shape of the multiplier function, i.e., $\omega=2$. Moreover, to avoid overestimating rate-related damages, we assume in the base scenario that damages increase only by moderate $2.5 \%$ if the rate of temperature increase is twice as high as the critical threshold, i.e. $\lambda=2.5$.

To put these assumptions into perspective, let us take for the moment the (not entirely correct) assumption that damages caused by the rate of temperature increase can be completely attributed to ecosystems and agriculture, which are presumably

\footnotetext{
18 As pointed out by two of the reviewers, different species, ecosystems and economic activities are subject to different critical thresholds. Hence, the multiplier function should rather have a partial staircase curvature with convex segments. Such an approach, however, would not only exacerbate the problem of finding suitable empirical data, but also tremendously increase the need for computational capacity. We therefore prefer to approximate the actual curvature of the function by a continuous convex shape.
} 
Table 1 Rate of temperature increase and magnitude of damage multiplier $\delta(t)$ in the "Business as usual"- and the "Immediate stop" case of DICE-2016R

\begin{tabular}{|c|c|c|c|c|c|c|}
\hline & 2020 & 2040 & 2060 & 2080 & 2100 & 2120 \\
\hline \multicolumn{7}{|c|}{ Rate of temperature increase $\left[{ }^{\circ} \mathrm{C} / \mathrm{dec}\right.$ ade $]$} \\
\hline Business as usual & 0.3392 & 0.3803 & 0.3995 & 0.3976 & 0.3761 & 0.3280 \\
\hline Immediate stop & 0.3019 & 0.1663 & 0.1091 & 0.0807 & 0.0624 & 0.0356 \\
\hline \multicolumn{7}{|c|}{ Magnitude of damage multiplier $\delta(t)$} \\
\hline Business as usual & 1.1510 & 1.2018 & 1.2258 & 1.2194 & 1.1823 & 1.1236 \\
\hline Immediate stop & 1.0760 & 1.0078 & 1.0001 & 1.0000 & 1.0000 & 1.0000 \\
\hline
\end{tabular}

The calculation of the damage multiplier relies on the assumptions of our base scenario

the two most affected fields. According to Nordhaus and Boyer (2000), these two fields account for about $15-20 \%$ of total damages caused by climate change. Hence, an increase in total damages by $2.5 \%$, as assumed in our base scenario for a warming of $0.2{ }^{\circ} \mathrm{C}$ per decade, would imply that the damages to ecosystems and agriculture increase by $12.5-16 . \overline{6} \%$.

To further illustrate the possible consequence of the assumptions used in our base scenario, it is useful to apply them to the "business as usual" case of DICE-2016R that relies on an indefinite extension of climate policies as in the year 2010. In this case, global mean temperature rises rapidly and would reach $+5{ }^{\circ} \mathrm{C}$ compared to pre-industrial levels already by the year 2120 . As a consequence, the threshold of $0.1^{\circ} \mathrm{C} /$ decade is heavily violated and the damage parameter $\delta(t)$ rises to a peak level of more than 1.22 (see Table 1) ${ }^{19}$ Calculated over the whole time horizon, the losses in the present value of net output caused by rate-related damages amount to about 51 trillion 2005 US- $\$$ or $0.74 \%$ in relative terms. ${ }^{20}$ Hence, even under the moderate assumptions of our base scenario, the extent of rate-related damages can become substantial if climate policies do not go beyond the status of 2010 .

Regarding the possibilities of reducing rate-related damages, however, it should be recognized that due to the inertia of the climate system and the longevity of $\mathrm{CO}_{2}$, there is already a "committed level of future warming" caused by past emissions (e.g., Frölicher et al. 2014). To illustrate the possible implications of this observation, we also analyzed an "immediate stop" case in DICE-2016R assuming that the mitigation rates are $100 \%$ already from the year 2015 (and that in 2150 they would jump to $120 \%$ as in the original model). ${ }^{21}$ As indicated in Table 1 , this leads to a sharp decline in the rates of temperature increase, but under the assumptions of our base scenario there will inevitably be some degree of rate-related damages during the first decades.

\footnotetext{
${ }^{19}$ Figures 11 and 12 in the Appendix show the evolution of greenhouse gas emissions and the accompanying temperature trajectory for the scenarios displayed in Table 1.

${ }^{20}$ These results have been calculated by running DICE-RD with the mitigation rates fixed to the "business as usual"-levels of DICE-2016R.

${ }^{21}$ To isolate the pure level of committed future warming, in this scenario we also fix the exogenous $\mathrm{CO}_{2}$ emissions from non-industrial activities to zero.
} 


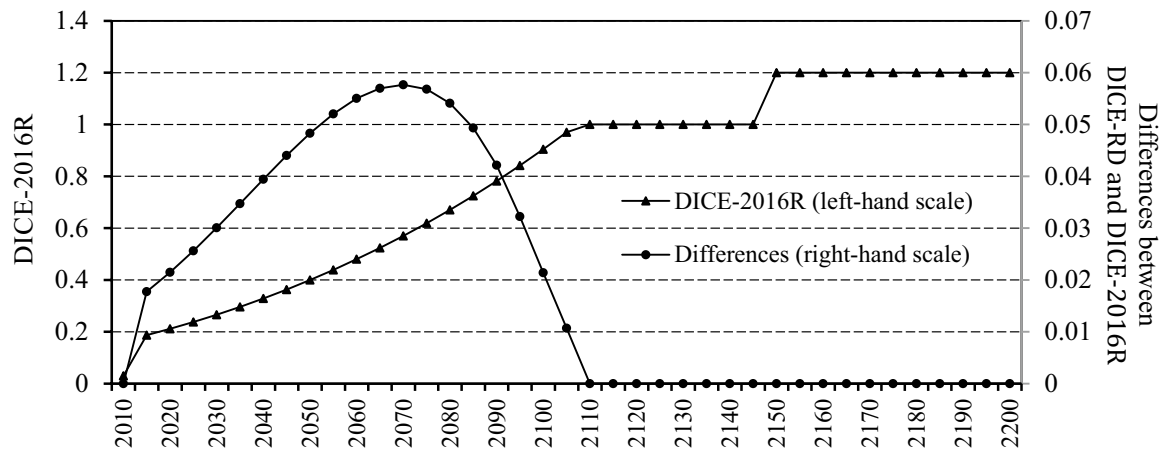

Fig. 2 Optimal mitigation rates. Left-hand scale: DICE-2016R. Right-hand scale: Differences between DICE-RD and DICE-2016R

Finally, we note that we are aware of the poor empirical foundation of our approach. The objective of the present study, however, is not an exact quantification of the impacts of rate-related damages. Rather, we want to elucidate the essential mechanisms, to describe possible scenarios and to narrow the range of likely outcomes by means of a comprehensive sensitivity analysis that covers a wide range of parameters.

\section{Results for the base scenario}

In this section, we discuss the results calculated using our modified model DICE-RD and compare them to the results of the original DICE-2016R model. ${ }^{22}$ As usual in studies based on DICE, we consider only the results for the first 200 years, although both models cover a time horizon of 500 years in total. ${ }^{23}$ The major endogenous policy variable is the mitigation rate $\mu(t)$ that describes the share of emissions avoided. For convenience, in the text mitigation rates are expressed as percentages, although in the original GAMS-files as well as in the figures below the variables $\mu(t)$ are expressed as decimals.

The left-hand scale of Fig. 2 indicates the optimal mitigation rates resulting from the original DICE-2016R model as calculated by Nordhaus (2018). For the first period, the mitigation rate is exogenously fixed. The first endogenously optimized mitigation rate occurs in 2015 with roughly $19 \%$. From that point on, the mitigation rates rise steadily until they reach their temporary upper limit of $100 \%$ in 2110 . Subsequently, in 2150 the mitigation rates jump to $120 \%$, since the upper limit is relaxed by the assumption that a "negative emissions" technology becomes available. ${ }^{24}$

\footnotetext{
22 All calculations have been performed using the GAMS-software version win64/24.1 with the BONMIN solver. The latter is capable of solving mixed integer problems, which is necessary due to the use of a binary variable. The program files are available from the corresponding author on request.

23 Considering a longer time span would even reinforce our results, since the vast majority of economic losses caused by neglecting rate-related damages occur not before the next century.

24 At present, one of the most promising technologies in development is the combination of bioenergy with carbon capture and storage (e.g., Azar et al. 2013, Fridahl and Lehtveer 2018). However, as emphasized by Anderson and Peters (2016), the tempting prospect that such technologies will become available on a large scale entails the danger that near-term mitigation measures are neglected.
} 
Table 2 Rate of temperature increase and magnitude of damage multiplier $\delta(t)$ in the optima of DICE2016R and DICE-RD

\begin{tabular}{|c|c|c|c|c|c|c|}
\hline & 2020 & 2040 & 2060 & 2080 & 2100 & 2120 \\
\hline \multicolumn{7}{|c|}{ Rate of temperature increase $\left[{ }^{\circ} \mathrm{C} /\right.$ decade $]$} \\
\hline DICE-2016R & 0.3343 & 0.3405 & 0.3249 & 0.2826 & 0.2150 & 0.1157 \\
\hline DICE-RD & 0.3337 & 0.3350 & 0.3136 & 0.2672 & 0.1983 & 0.1063 \\
\hline \multicolumn{7}{|c|}{ Magnitude of damage multiplier $\delta(t)$} \\
\hline DICE-2016R & 1.1372 & 1.1450 & 1.1265 & 1.0842 & 1.0330 & 1.0006 \\
\hline DICE-RD & 1.1366 & 1.1381 & 1.1141 & 1.0700 & 1.0242 & 1.0001 \\
\hline
\end{tabular}

The calculation of the damage multiplier relies on the assumptions of our base scenario

The right-hand scale of Fig. 2 indicates the results of our own calculations using DICE-RD with the base assumptions $\lambda=2.5, \omega=2$ and $v=0.1$. To enhance the graphical depiction, we do not display the absolute mitigation rates, but their differences to the original mitigation rates resulting from DICE-2016R. As shown in Fig. 2, these differences increase steadily until they reach a peak level of almost six percentage points around the year 2070. Afterward, they converge back to zero in 2110. The reason for the latter behavior is straightforward, since in 2110 the mitigation rates in both models reach their limit of $100 \%$ such that no more differences occur.

Moreover, Figs. 11 and 12 in the Appendix show the evolution of greenhouse gas emissions and the accompanying temperature trajectory resulting from DICE-2016R and DICE-RD. In both models, the time path of emissions and global mean temperature exhibit the same shape. After a period of increase driven by economic growth, emissions start to decrease around the year 2040, tend to zero in 2110 and become negative in 2150 . Due to the inertia of the climate systems, global mean temperature continues to increase until 2165 and starts to decrease afterward. However, in DICERD emissions are significantly lower than in DICE-2016R and the rise in temperature is slightly slowed down. Although the threshold of $0.1^{\circ} \mathrm{C}$ per decade is violated in both models during the first 120 years, the rate of temperature increase and the accompanying damage multiplier $\delta(t)$ are lower in DICE-RD than in DICE-2016R (see Table 2).

At first glance, the differences between DICE-2016R and DICE-RD shown in Table 2 might seem to be almost negligible, since only a small part of rate-related damages is avoided. However, as the following analysis will show, the economic losses caused by neglecting rate-related damages can be significant. The calculation of these losses is performed in three steps ${ }^{25}$ :

-In the first step, we calculate the net output that results if the optimal mitigation rates as derived from DICE-RD are employed.

\footnotetext{
25 In Wirths et al. (2018), we use a similar calculation to quantify the economic losses caused by neglecting the permafrost carbon feedback in the determination of optimal mitigation.
} 


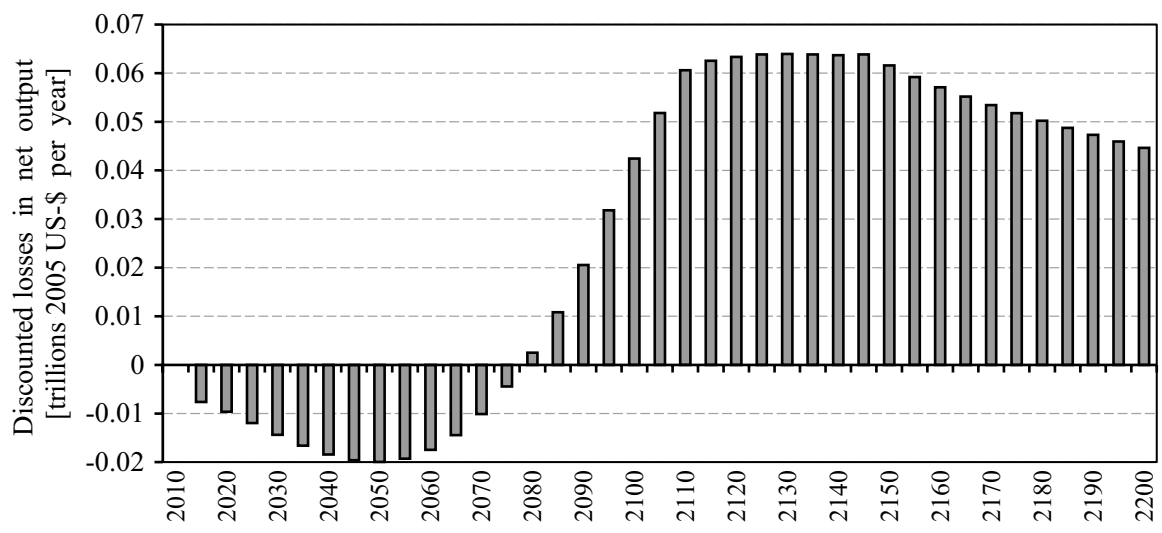

Fig. 3 Discounted losses in net output if rate-related damages are ignored (base scenario)

-In the second step, we run DICE-RD with exogenous mitigation rates that are fixed to the levels resulting from the original model DICE-2016R as shown at the left-hand scale of Fig. 2. Hence, for roughly the first 100 years, we force DICE$\mathrm{RD}$ to employ suboptimal low rates. This yields the net output that results if the applied mitigation rates neglect rate-related damages, although they are present in the model.

-In the third step, the differences in net output between the optimal run (first step) and the run with fixed mitigation rates (second step) are calculated. The present value of these differences can be interpreted as the economic losses caused by a climate policy that neglects rate-related damages. ${ }^{26}$

The results of this comparison in discounted trillions of 2005 US-\$ per year are shown in Fig. $3 .{ }^{27}$ Remarkably, the output losses for roughly the first 70 years are negative. This implies that actually the suboptimal climate policy, which ignores rate-related damages, is economically beneficial in those periods. The reason is obvious, since the optimal climate policy requires higher mitigation rates. This leads immediately to higher mitigation costs, whereas the majority of the benefits in terms of a lower increase in temperature accrue in the distant future. Consequently, when considering only the first couple of periods, employing suboptimal low mitigation rates leads to an increase in net output. Around the year 2080, however, this situation would change drastically. The output losses caused by ignoring rate-related damages become positive and increase sharply. The reason is that the optimal mitigation rates converge to the original rates resulting from DICE-2016R as shown in Fig. 2. Hence, in the following decades, the additional mitigation costs implied

\footnotetext{
${ }^{26}$ For discounting, we use the real interest rates resulting from DICE-2016R. These rates are declining in time: they range from $5.1 \%$ p.a. for the first period to $2.8 \%$ p.a. for the last period of the time horizon considered.

27 The same calculation can be performed for the variables consumption and investments. Apart from the absolute values, the resulting diagrams are mostly similar to those for net output.
} 
by the optimal climate policy tend to zero, but the economy still benefits from less damage due to the increased mitigation rates in the past. Aggregated over the complete time horizon, the present value of losses in net output amounts to 5.3 trillion 2005 US-\$. Compared to the present value of aggregated net output in the optimum of DICE-RD, this implies relative losses of only about $0.08 \%$. However, since most of the output losses occur in the distant future, this figure might be biased by discounting (see also Sect. 7.2).

In terms of intergenerational equity, our results imply that present generations living until 2080 would benefit from neglecting rate-related damages, whereas future generations living afterward will have to bear a high additional burden. In terms of present value, the output losses accumulated after 2080 are about 7.5 times as high as the growth in output generated in the time span before. Hence, the intergenerational conflict caused by climate change is exacerbated even further.

\section{Sensitivity analysis}

As a general shortcoming, the results of IAMs like DICE crucially depend on the magnitude of several parameters, which are highly uncertain or at least disputed in the literature (see Sect. 3). The need to fix the parameters of our multiplier function (7) adds even more uncertainty to the model, since the extent to which the rate of temperature increase affects ecological and social systems is poorly understood. Therefore, in Sect. 7.1, we analyze the effects caused by varying the parameters of the multiplier function.

Moreover, one of the most important-but also most controversially discussedparameters influencing optimal mitigation is the pure rate of social time preference. Concerning the issue under consideration, the effects of discounting might even be stronger, since the output losses caused by neglecting rate-related damages mainly occur in the distant future. Consequently, the effects of varying the pure rate of social time preference are analyzed in Sect. 7.2.

\subsection{Parameters of the multiplier function}

As already emphasized in Sect. 5, the parameter $\lambda$ describes the percentage by which total damages increase if the rate of temperature increase is twice as high as the critical threshold. In our base scenario, we assumed $\lambda=2.5$. Now, we consider two additional cases: A "low damage" scenario with $\lambda=1$ and a "high damage" scenario with $\lambda=5$. As expected, an increase in $\lambda$ reinforces the differences in mitigation rates, whereas a decrease in $\lambda$ causes the opposite effect (see Fig. 4). However, even in the "low damage" scenario we still obtain non-negligible differences that peak at about 2.5 percentage points around 2070 .

For all three scenarios, the discounted losses in net output caused by ignoring rate-related damages follow the same general trend (see Fig. 5): At the beginning of 


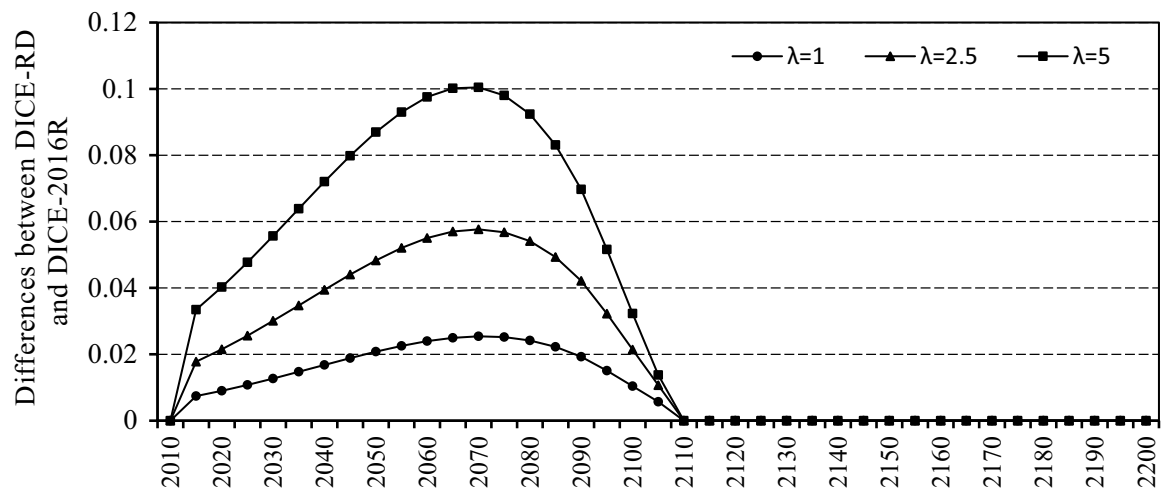

Fig. 4 Optimal mitigation rates: differences between DICE-RD and DICE-2016R for varying damage parameters $\lambda$ (assuming $\omega=2$ and $\nu=0.1$ )

the time horizon, they are slightly negative, but later on, they become positive and start to increase more or less sharply. The only difference relates to their absolute levels: in the "high damage" scenario the present value of aggregated losses in net output increases up to 11.2 trillion US-\$ implying relative losses of about $0.17 \%$. In the "low damage" scenario, the present value of losses shrinks down to 2 trillion US-\$ or about $0.03 \%$, respectively.

Next, we turn to the effects of changing the parameter $\omega$ that determines the convexity of the multiplier function $\delta(t)$. In addition to the quadratic case with $\omega=2$ considered above, we analyze a linear specification $\omega=1$ and a cubic specification $\omega=3 .^{28}$ Compared to the quadratic specification, the linear one implies that rates of temperature increase below the calibration point of $0.1^{\circ} \mathrm{C}$ per period lead to higher damages, whereas rates above $0.1{ }^{\circ} \mathrm{C}$ per period lead to lower damages. The opposite effects occur when switching from the quadratic to the cubic specification. The results of these calculations are shown in Figs. 13 and 14 in the Appendix. Except for a short time span around 2090-2110, increasing or decreasing the parameter $\omega$ has essentially the same effects as increasing or decreasing $\lambda$ (albeit the absolute magnitude of the effects is different). Using the cubic instead of the quadratic specification increases the relative losses in the present value of net output from $0.08 \%$ up to $0.22 \%$, whereas using the linear specification we obtain a decline to roughly $0.03 \%$.

Finally, we analyze changes in the critical threshold for rate-related damages. Proceeding from the magnitude of $0.1{ }^{\circ} \mathrm{C} /$ decade assumed so far, we consider a less severe threshold of $0.2{ }^{\circ} \mathrm{C} / \mathrm{dec} a d e$ and a more severe one of $0.05{ }^{\circ} \mathrm{C} / \mathrm{dec}$ de as suggested by the literature (see Sect. 2). For both cases, we again assume $\lambda=2.5$ and the quadratic specification $\omega=2$. Figures 15 and 16 in the Appendix show the results of these calculations. Assuming the less severe threshold of $0.2{ }^{\circ} \mathrm{C} /$ decade, the impacts of rate-related damages vanish almost completely, since the optimal

\footnotetext{
${ }^{28}$ We are aware that the linear specification is a limiting case that is actually unrealistic in view of the present state of knowledge (see section 5).
} 


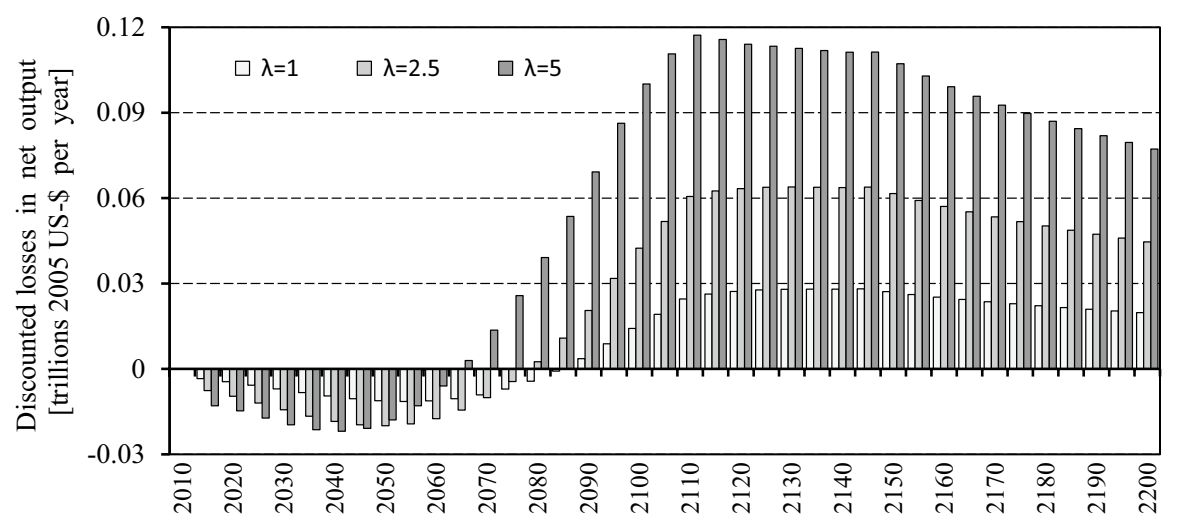

Fig. 5 Discounted losses in net output for varying damage parameters $\lambda$ (assuming $\omega=2$ and $\nu=0.1$ )

solution of the original DICE-2016R violates this threshold only slightly during the first couple of periods. In contrast, for a threshold of $0.05^{\circ} \mathrm{C} / \mathrm{dec}$ ade, the differences in mitigation rates almost quadruple compared to the base scenario. Consequently, the losses in the present value of net output increase up to 37 trillion US-\$ implying relative losses of about $0.57 \%$. These results show that the economic effects of raterelated damages react rather sensitively to changes in the critical threshold.

Figure 6 summarizes the results from our sensitivity analysis in terms of the relative losses in the present value of net output caused by ignoring rate-related damages. Overall, these results suggest that potential economic impacts of rate-related damages range from almost negligible $0.03 \%$ to a more substantial $0.57 \%$.

The variations considered in the sensitivity analysis above, however, can also occur simultaneously thereby reinforcing each other. Hence, to illustrate the possible extent of the problem at hand, we additionally calculated a "worst case" scenario that combines the most critical assumptions. In detail, we assumed that the multiplier function $\delta(t)$ is cubic, the threshold for the occurrence of raterelated damages amounts to $0.05{ }^{\circ} \mathrm{C}$ per decade, and total damages increase by

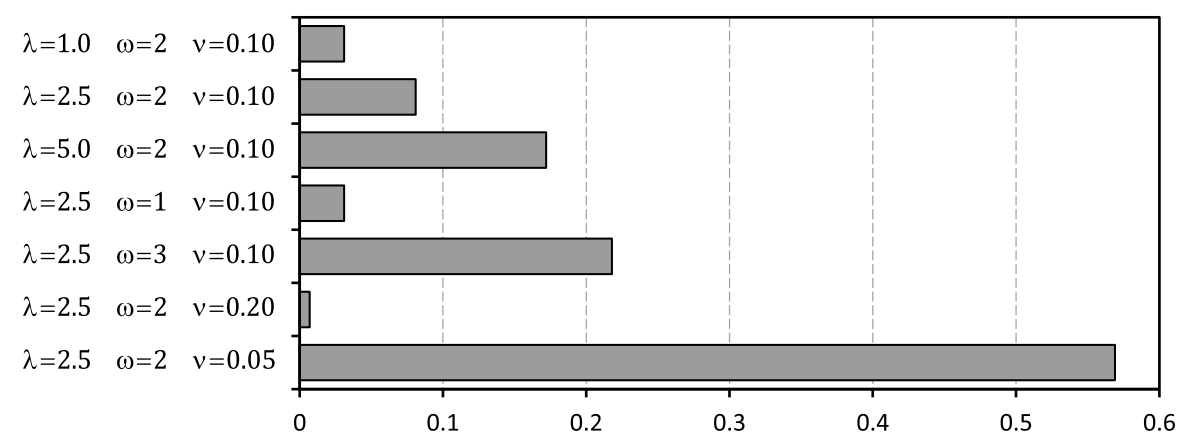

Fig. 6 Summary of sensitivity analysis: Relative losses in present value of net output [\%] 
$5 \%$ if the rate of temperature increase is twice as high as the critical threshold. As a result, we found that the differences in mitigation rates would rise to a peak level of about 48 percentage points already around 2040, and the losses in the present value of net output amount to 485 trillion US-\$ or about $7.6 \%$, respectively. Hence, under"worst case" assumptions, which cannot be ruled out completely at the present state of knowledge, rate-related damages can lead to serious economic losses.

\subsection{Pure rate of social time preference}

In the following, we again refer to the base scenario with $\lambda=2.5, \omega=2$ and a threshold of $0.1{ }^{\circ} \mathrm{C}$ per decade, but now we consider the impacts caused by reducing the pure rate of social time preference $\rho$ from $1.5 \%$ (as used so far) to $1 \%$ and $0.5 \%$. Of course, to guarantee comparability, the lower values of $\rho$ are employed in our extended model DICE-RD as well as in the original model DICE-2016R. In both models, decreasing $\rho$ causes the mitigation rates to increase more rapidly, since future climate damages gain more weight against early mitigation costs. In DICE2016R, however, these effects are stronger than in DICE-RD. Consequently, lowering the rate of social time preference diminishes the differences in mitigation rates (see Fig. 7). Moreover, the smaller the $\rho$, the earlier the mitigation rates approach their upper limit of $100 \%$ such that differences converge back to zero.

Of course, the diminishing differences in mitigation rates have a strong impact on the losses in net output caused by neglecting rate-related damages. The absolute (i.e., undiscounted) losses behave as expected and decline by roughly $50 \%$ for $\rho=0.01$ and $80 \%$ for $\rho=0.005$. The discounted losses depicted in Fig. 8, however, behave less clearly. Summing up, their present value yields a result that is somewhat puzzling at first glance: reducing $\rho$ from 1.5 to $1 \%$, we obtain a slight increase in losses from 5.3 to 5.5 trillion US-\$, whereas a further reduction of $\rho$ down to $0.5 \%$ induces a decrease to 4 trillion US-\$. The answer to this puzzle is that lowering the rate of social time preference does not only increase mitigation rates, but also it has two additional effects: it increases total output via a higher degree of capital accumulation and at the same time it diminishes the real interest rates to be used for discounting. ${ }^{29}$ Consequently, it seems to be more sensible to compare relative figures that are less distorted by these effects. If we look at our calculations in this way, we obtain a clear-cut result: reducing $\rho$ always reduces the relative losses in the present value of net output. For $\rho=0.01$, the relative losses drop down from 0.08 to $0.06 \%$, and for $\rho=0.005$ they drop down further to $0.025 \%$. Consequently, if the planner uses a sufficiently low rate of social time preference to determine the optimal mitigation path, a good deal of the economic losses caused by neglecting rate-related damages will be avoided because optimal mitigation rates are higher.

\footnotetext{
${ }^{29}$ With $\rho=0.01$, the real interest rates range from $4.8 \%$ p.a. for the first period to $2.3 \%$ p.a. for the last period of the considered time horizon. For $\rho=0.005$, the corresponding figures are $4.5 \%$ and $1.8 \%$.
} 


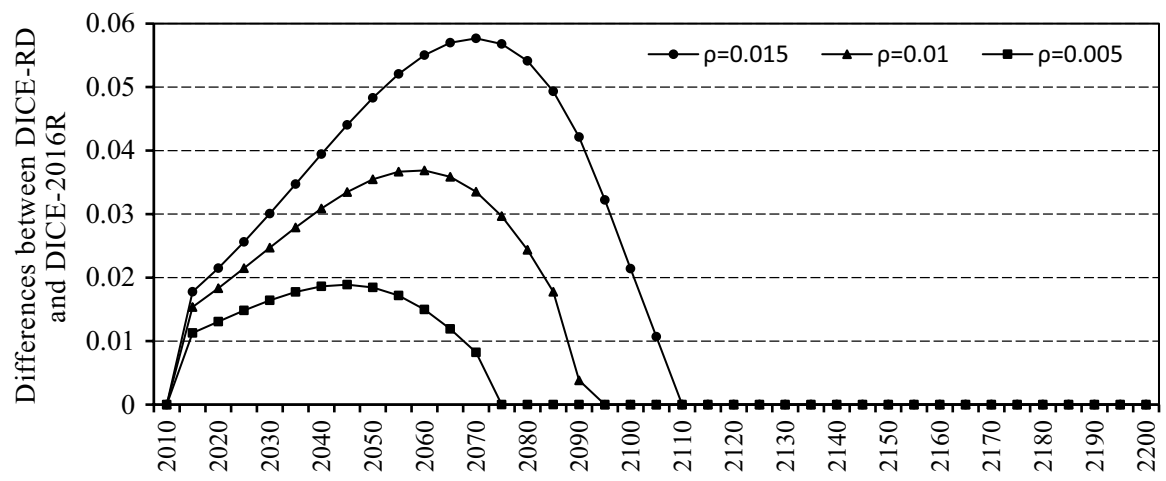

Fig. 7 Optimal mitigation rates: differences between DICE-RD and DICE-2016R for varying rates of social time preference $\rho$

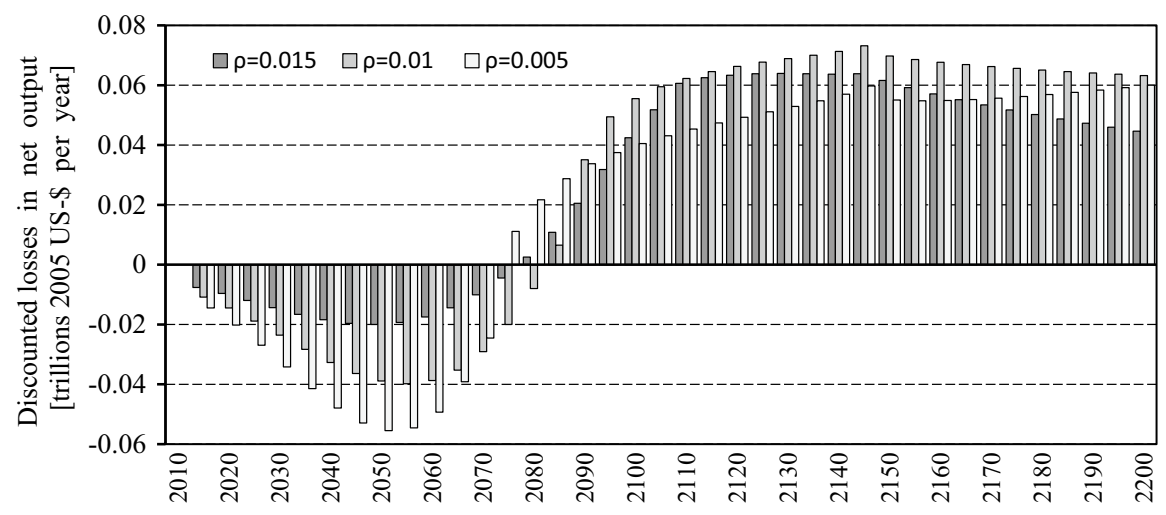

Fig. 8 Discounted losses in net output for varying rates of social time preference $\rho$

\section{The case of a fixed temperature target}

Concerning the previous analysis, it could be objected that today's climate policy does not seek to enforce an economically optimal mitigation path, but pursues a politically fixed temperature target that is well below the optimum level derived from the DICE model. Under the Copenhagen Agreement, the international community focused on keeping the temperature increase compared to the pre-industrial level below $2{ }^{\circ} \mathrm{C}$, and under the Paris Agreement, this target has been tightened to $1.5{ }^{\circ} \mathrm{C}$. Within DICE-2016R, however, the target of $1.5^{\circ} \mathrm{C}$ is not attainable at all, and the feasibility of the $2{ }^{\circ} \mathrm{C}$ target would require a substantial adjustment of the model so that large-scale "negative emissions" technologies will not be available 
only from 2150 as mentioned in Sect. 6, but already in the near term (Nordhaus 2019). We therefore follow the approach taken by Nordhaus (2018) and consider the less ambitious target of $2.5^{\circ} \mathrm{C} .{ }^{30}$

Before proceeding, it has to be emphasized that the DICE model's problems to cope with the temperature targets of 1.5 and $2{ }^{\circ} \mathrm{C}$ do not imply at all that these targets are unattainable for climate policy. As shown by the projections of the IPCC (2014c, Chapter 6), there exist several mitigation pathways that stabilize the greenhouse gas concentration in the atmosphere at a level of 450-500 ppm during this century, thereby ensuring with high confidence that the increase in global mean temperature will be kept below $2{ }^{\circ} \mathrm{C}$. Moreover, under more pronounced and more rapid mitigation efforts, even the target of $1.5{ }^{\circ} \mathrm{C}$ is still achievable (IPCC 2018, Chapter 2). This apparent contradiction to the results of the DICE model has mainly two reasons. First, in contrast to DICE, the largescale IAMs, which are used for the projections of the IPCC, usually include a complex representation of the energy sector that allows for a more detailed analysis of mitigation options. Second, the IPPC projections reaching the $2{ }^{\circ} \mathrm{C}$ target often rely on the widespread deployment of "negative emissions" technologies already in the second half of the century (IPCC, 2014, p. 12). This is in contrast to the more pessimistic assumptions about the availability of these technologies employed in the DICE model.

As shown at the left-hand scale of Fig. 9, maximizing welfare in DICE-2016R under the additional restriction $T_{\mathrm{AT}}(t) \leq 2.5$ leads to sharply increasing mitigation rates that reach their temporary limit of $100 \%$ already in 2035 before they jump again to $120 \%$ in 2150 . As a result, compared to the unrestricted optimum discussed in Sect. 6, the rise in temperature is slowed down and rate-related damages are reduced considerably. Hence, if climate policy successfully pursues the $2.5^{\circ} \mathrm{C}$ target along the optimal trajectory calculated by DICE-2016R, the incentive for additional mitigation measures that aim at reducing rate-related damages would decline and the time frame available for taking such measures would shrink down to a short time period until 2035.

Due to these effects, the differences in mitigation rates between DICE-2016R and DICE-RD vanish almost completely if we assume our base scenario with a damage parameter of $\lambda=2.5$ and a threshold of $0.1^{\circ} \mathrm{C}$ per decade. Noticeable differences only occur if the corresponding assumptions are tightened. To derive an (possible) upper limit for the impact of rate-related damages on mitigation rates, we use the "worst case" scenario introduced in Sect. 7.1. Under these assumptions, accounting for rate-related damages leads to a re-allocation of abatement activities during the first couple of periods (see Fig. 9, right hand scale): Beginning with

${ }^{30}$ This target seems also to be more realistic in view of the national-level commitments on reducing $\mathrm{CO}_{2}$ emissions under the Paris Agreement (Rogelj et al. 2016). 


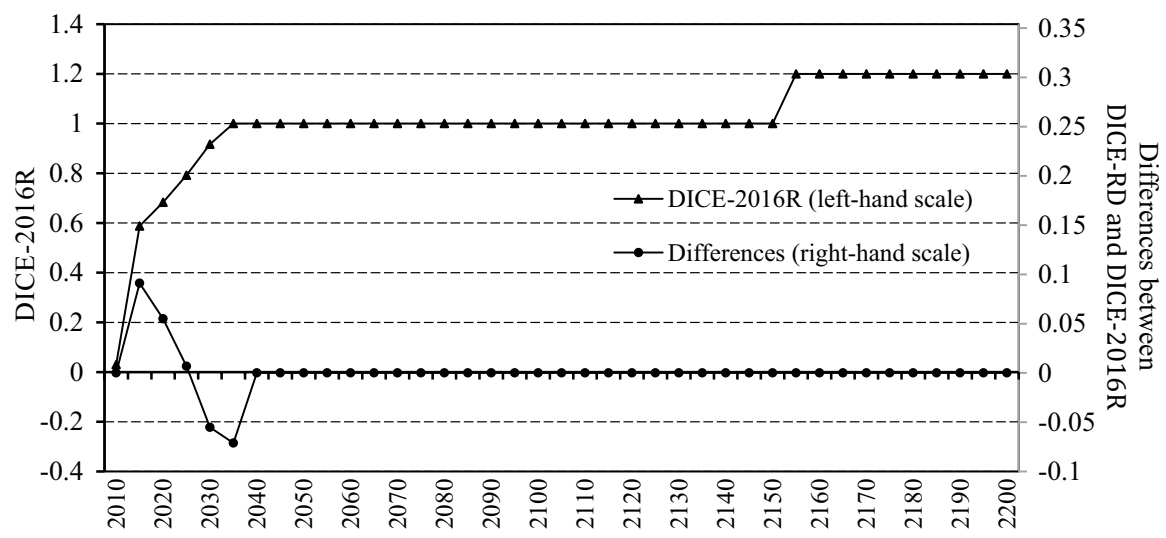

Fig. 9 Optimal mitigation rates for the $2.5^{\circ} \mathrm{C}$ target. Left-hand scale: DICE-2016R. Right-hand scale: differences between DICE-RD and DICE-2016R ("worst case" scenario)

2015 , in the first three periods, the optimal mitigation rates increase by up to about 9 percentage points, and in the next two periods an opposite effect occurs. ${ }^{31}$ Afterward, there are no more differences because the mitigation rates in both models reach their upper limit of $100 \%$.

Moreover, Fig. 10 shows the discounted losses in net output that occur if climate policy ignores rate-related damages and employs the mitigation rates resulting from DICE-2016R as shown at the left-hand scale of Fig. 9. During the first three periods beginning in 2015, the losses are negative such that the net output increases. In the following periods, the losses become positive, but they decline rapidly over time and already after two decades, they would be barely noticeable. Aggregated over the complete time horizon, we observe a slight increase in the present value net output that amounts to 3.2 trillion 2005 US-Dollar or $0.05 \%$, respectively. At first glance, this result might seem somewhat surprising. However, it should be borne in mind that the DICE model does not maximize the present value of net output, but the level of total welfare as given by (2), and the latter figure actually decreases slightly by $0.025 \%$ if rate-related damages are ignored. ${ }^{32}$

The implications of the above analysis are obvious: if climate policy succeeds in restricting the absolute increase in temperature to $2.5^{\circ} \mathrm{C}$ (or even below) along a steady time path, the rate of temperature increase will be slowed down considerably and additional mitigation measures aiming at a further reduction of rate-related damages are hardly feasible or necessary. Such a policy, however, would require mitigation rates of $100 \%$ already in the near future.

\footnotetext{
31 Note that both effects almost completely cancel each other out, such that the cumulative carbon emissions at the beginning of 2040 remain virtually constant.

32 This negative effect on welfare is mainly driven by the change in the intertemporal distribution of net output during the first couple of periods.
} 


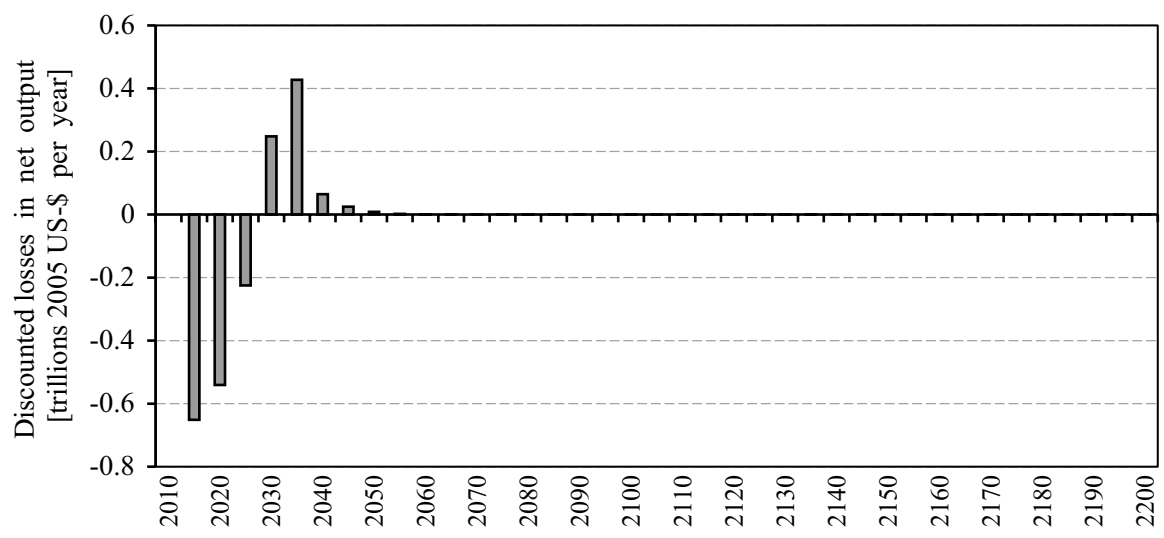

Fig. 10 Discounted losses in net output if rate-related damages are ignored in case of the $2.5^{\circ} \mathrm{C}$ target ("worst case" scenario)

\section{Summary and conclusions}

Given the growing evidence concerning the importance of the rate of temperature increase, neglecting this aspect is an obvious shortcoming in the economics of climate change. Especially IAMs that aim at calculating optimal mitigation rates should incorporate all sources of damages to generate reliable results. In the present paper, we contributed to the corresponding literature in four ways:

-First, we showed how to incorporate damages caused by the rate of temperature increase into the well-known DICE-2016R model. In doing so, we particularly accounted for the hitherto neglected fact that rate-related damages are only likely to occur when the rate of temperature increase exceeds a certain threshold that overstrains the adaptive capacity of ecological and social systems. Moreover, we decided to model the relationship between damages caused by the absolute level of temperature increase and damages caused by the rate of temperature increase in a multiplicative instead of an additive manner. The reason is that systems, which are already disturbed by the absolute level of temperature increase, will probably have more problems coping with the additional stress stemming from a high rate of temperature increase.

-Second, using our modified model DICE-RD we analyzed various scenarios to derive a large range of simulation results. A climate policy, which relies on the mitigation rates resulting from the original DICE-2016R model, can lead to significant rate-related damages, since it implies a rate of temperature increase that considerably exceeds the best-guess threshold of $0.1{ }^{\circ} \mathrm{C} / \mathrm{decade}$ during the current century. Accounting for these potential damages, optimality requires a considerable increase in mitigation rates.

-Third, we quantified the losses in net output caused by an insufficient climate policy that ignores rate-related damages. Depending on the scenario considered, the relative losses in the present value of net output compared to 
the optimal solution range from almost negligible $0.03 \%$ to more substantial $0.57 \%$. An even more severe impact, however, cannot be ruled out completely at the present state of insights. Although the vast majority of output losses occur in the distant future, everything else equal, the higher the applied rate of social time preference, the higher the present value of relative losses. Consequently, a sufficiently low rate of social time preference when determining the mitigation path to be realized by climate policies could avoid a good deal of the economic losses caused by neglecting rate-related damages.

-Fourth, we analyzed the case of a politically fixed temperature target of $2.5^{\circ} \mathrm{C}$ that requires mitigation rates of $100 \%$ already in the near future. If such a policy is successful, the rate of temperature increase will be slowed down considerably and additional measures aiming at a further reduction of rate-related damages are hardly feasible or necessary. Hence, rate-related damages might be another reason to pursue an ambitious temperature target.

However, the limitations of our work are obvious. Besides the well-known criticisms of DICE and related models (see Sect. 3), it should be emphasized that our extension of DICE-2016R adds further uncertainties to the analysis. Although it seems to be possible to narrow the empirical range of the critical threshold for the rate of temperate increase, there are no reliable data on the specific magnitude of rate-related damages available from the literature. Hence, we utilized scenario analysis to illustrate the potential effects of such damages. To increase the reliability of our results, it is necessary to narrow the empirical parameterization of our extended damage function. For this purpose, much more research is required in the natural as well as in the social sciences. Since the vulnerability to the rate of temperature increase most likely differs across regions, an application of our approach to the regionally disaggregated RICE-model (Nordhaus and Boyer 2000) would be an interesting route of further research depending on the future availability of reliable regional data.

Acknowledgements Open Access funding provided by Projekt DEAL. We are grateful to Thomas Ziesemer (University of Augsburg) and the three anonymous reviewers for helpful comments and suggestions. All remaining errors are ours.

Open Access This article is licensed under a Creative Commons Attribution 4.0 International License, which permits use, sharing, adaptation, distribution and reproduction in any medium or format, as long as you give appropriate credit to the original author(s) and the source, provide a link to the Creative Commons licence, and indicate if changes were made. The images or other third party material in this article are included in the article's Creative Commons licence, unless indicated otherwise in a credit line to the material. If material is not included in the article's Creative Commons licence and your intended use is not permitted by statutory regulation or exceeds the permitted use, you will need to obtain permission directly from the copyright holder. To view a copy of this licence, visit http://creativecommons.org/licen ses/by/4.0/.

\section{Appendix}

See appendix Figs. 11, 12, 13, 14, 15, 16 


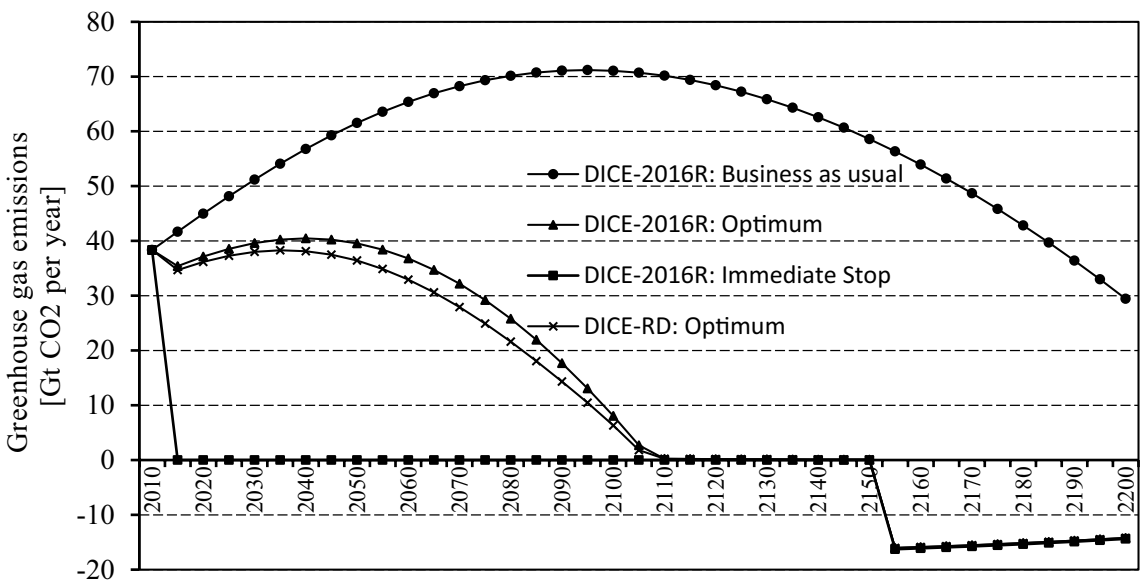

Fig. 11 Greenhouse gas emissions in different scenarios of DICE-2016R (business as usual, optimum and immediate stop) and in DICE-RD (optimum)

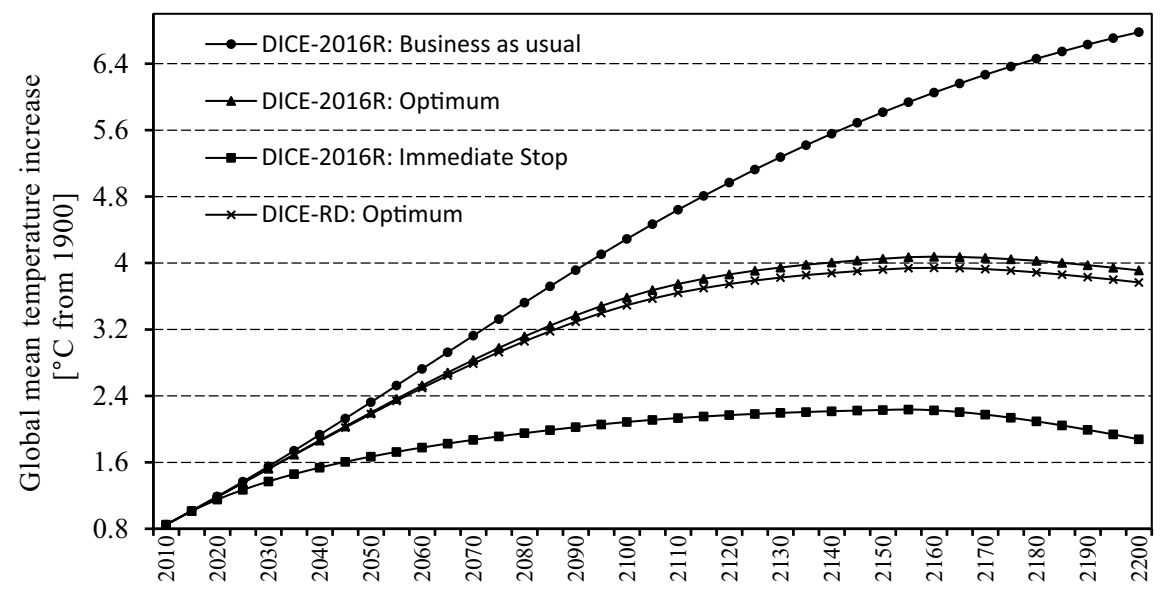

Fig. 12 Increase in global mean temperature in different scenarios of DICE-2016R (business as usual, optimum and immediate stop) and in DICE-RD (optimum) 


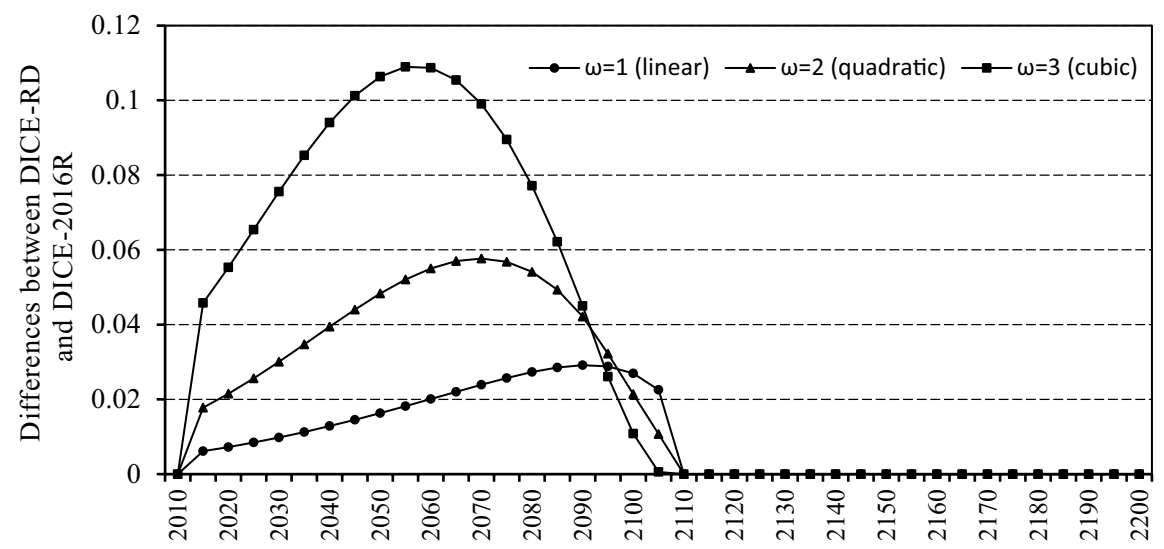

Fig. 13 Optimal mitigation rates: Differences between DICE-RD and DICE-2016R for varying convexity parameters $\omega$ (assuming $\lambda=2.5$ and $v=0.1$ )

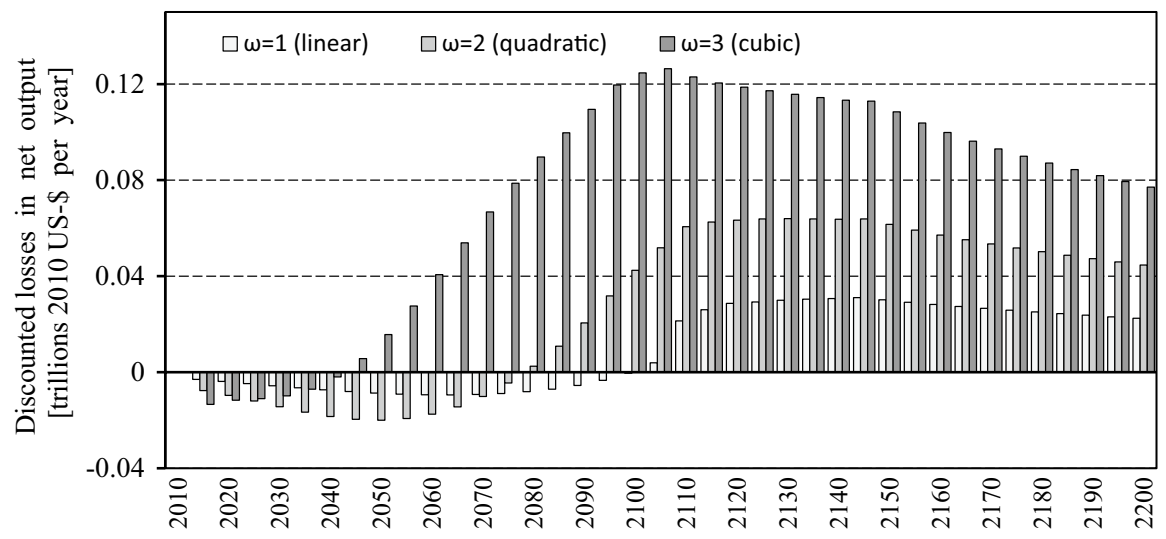

Fig. 14 Discounted losses in net output for varying convexity parameters $\omega$ (assuming $\lambda=2.5$ and $v=0.1)$ 


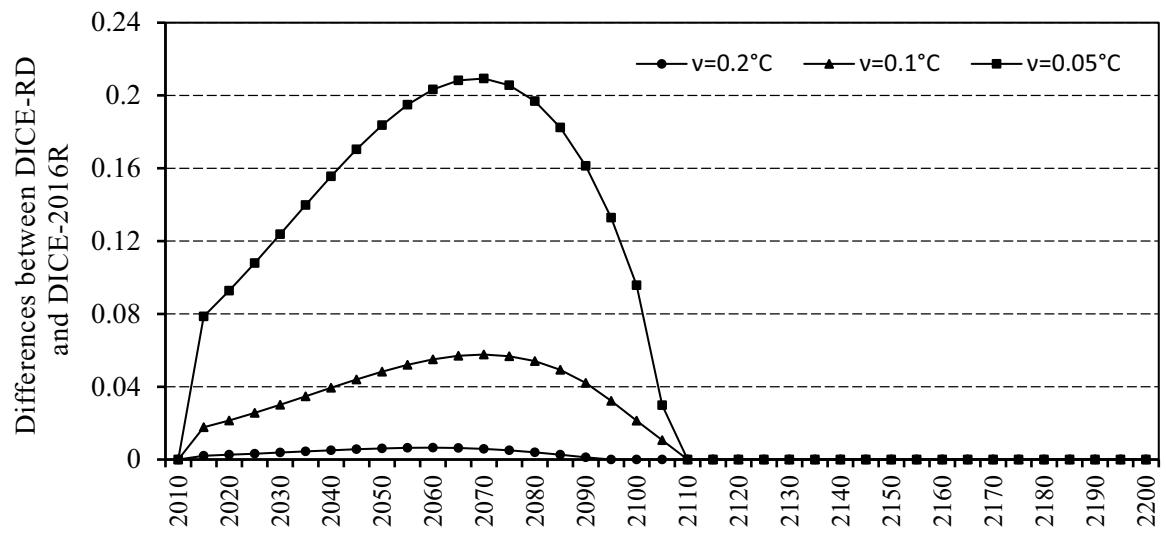

Fig. 15 Optimal mitigation rates: differences between DICE-RD and DICE-2016R for varying thresholds $\nu$ (assuming $\lambda=2.5$ and $\omega=2$ )

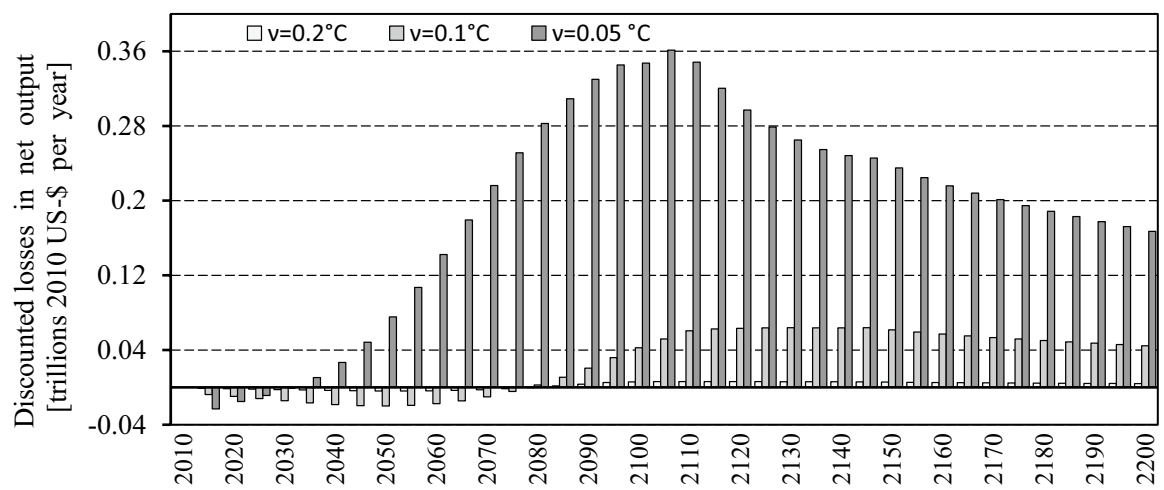

Fig. 16 Discounted losses in net output for varying thresholds $v$ (assuming $\lambda=2.5$ and $\omega=2$ )

\section{References}

Ackerman F, DeCanio SJ, Howarth RB, Sheeran K (2009) Limitations of integrated assessment models of climate change. Clim Change 95:297-315

Anderson K, Peters G (2016) The trouble with negative emissions. Science 354:182-183

Arrow KJ, Cropper ML, Gollier C, Groom B, Heal GM, Newell RG, Nordhaus WD, Pindyck RS, Pizer WA, Portney PR, Sterner T, Tol RSJ, Weitzman ML (2014) Should governments use a declining discount rate in project analysis? Rev Environ Econ Policy 8:145-163

Azar C, Johansson DJA, Mattson N (2013) Meeting global temperature targets: the role of bioenergy with carbon capture and storage. Environ Res Lett 8:1-8

Bellon MR, Hodson D, Hellin J (2011) Assessing the vulnerability of traditional maize seed systems in Mexico to climate change. Proc Natl Acad Sci USA 108:13432-13437

Bhatti J, Jassal R, Black TA (2012) Decarbonization of the atmosphere: role of the boreal forest under changing climate. In: Lal R, Lorenz K, Hüttl R, Schneider B, Braun J (eds) Recarbonization of the biosphere. Springer, Dordrecht, pp 203-228

Böhringer C, Löschel A, Rutherford T (2006) Efficiency gains from "what"-flexibility in climate policy-an integrated CGE assessment. Energ J 27:405-424 
Bommarco R, Vico G, Hallin S (2017) Exploiting ecosystem services in agriculture for increased food security. Glob Food Secur 17:57-63

Brady MV, Hedlund K, Cong RG, Hemerik L, Hotes S, Machado S, Mattsson L, Schulz E, Thomsen IK (2015) Valuing supporting soil ecosystem services in agriculture: a natural capital approach. Agron J 107:1809-1821

Burke M, Dykema J, Lobell DB, Miguel E, Satyanath S (2015a) Incorporating climate uncertainty into estimates of climate change impacts. Rev Econ Stat 97:461-471

Burke M, Hsiang SM, Miguel E (2015b) Climate and Conflict. Annu. Rev Econ 7:577-617

Burke M, Davis WM, Diffenbaugh N (2018) Larger potential reduction in economic damages under UN mitigation targets. Nature 557:549-553

Christmas MJ, Breed MF, Lowe AJ (2016) Constraints to and conservation implications for climate change adaption in plants. Conserv Genet 17:305-320

Corlett RT, Westcott DA (2013) Will plants movements keep up with climate change? Trends Ecol Evol 28:482-488

Cox PM, Betts RA, Collins M, Harris PP (2004) Amazonian forest dieback under climate-carboncycle projections for the 21st century. Theor Appl Climatol 78:137-156

Dasgupta P (2008) Discounting climate change. J Risk Uncertain 37:141-169

Farmer JD, Hepburn C, Mealy P, Teytelboym A (2015) A third wave in the economics of climate change. Environ Resour Econ 62:329-357

Fridahl M, Lehtveer M (2018) Bioenergy with carbon capture and storage (BECCS): global potential, investment preferences, and deployment barriers. Energy Res Soc Sci 42:155-166

Frölicher TL, Winton M, Sarmiento JL (2014) Continued global warming after $\mathrm{CO}_{2}$ emissions stoppage. Nat Clim Change 4:40-44

Fujimori S, Masui T, Matsuoka Y (2012) AIM/CGE [basic] manual. Discussion Paper 2012-01, Center for Social and Environmental Systems Research, Tsukuba, Japan.

Gambhir A, Butnar I, Li PH, Smith P, Strachan N (2019) A review of criticisms of integrated assessment models and proposed approaches to address these, through the lens of BECCS. Energies $12: 1747$

Goulder LH, Williams RC (2012) The choice of discount rate for climate change policy evaluation. Clim Change Econ 3:1250024

Grubb M, Hourcade JC, Neuhoff K (2014) Planetary Economics. Routledge, London, New York

Heal GM, Millner A (2014) Agreeing to disagree on climate policy. Proc Natl Acad Sci USA 111:3695-3698

Hof AF, Hope CW, Lowe J, Mastrandrea MD, Meinshausen M, van Vuuren DP (2012) The benefits of climate change mitigation in integrated assessment models: the role of the carbon cycle and climate component. Clim Change 113:897-917

Hope C (2006) The marginal impact of $\mathrm{CO}_{2}$ from PAGE2002: An integrated assessment model incorporating the IPCC's five reasons for concern. Integr Assess J 6(1):19-56

Hope $\mathrm{C}$ (2013) Critical issues for the calculation of the social cost of $\mathrm{CO}_{2}$ : why the estimates from PAGE09 are higher than those from PAGE2002. Clim Change 116:531-543

Howard P, Sterner T (2017) Few and not so far between: a meta-analysis of climate damage estimates. Environ Resour Econ 68:197-225

Howden SM, Soussana JF, Tubiello FN, Chhetri N, Dunlop M, Meinke H (2007) Adapting agriculture to climate change. Proc Natl Acad Sci USA 104:19691-19696

Hsiang SM, Burke M (2014) Climate, conflict, and social stability: what does the evidence say? Clim Change 123:39-55

IPCC (1996) Integrated assessment of climate change: an overview and comparison of approaches and results [Weyant J, Davidson O, Dowlatabadi H, Edmonds J, Grubb M, Parson EA, Richels R, Rotmans J, Shukla PR, Tol RSJ, Cline W, Fankhauser S]. In: Climate change 1995: economic and social dimensions of climate change. Contribution of working group III to the second assessment report of the Intergovernmental Panel on Climate Change [Bruce JP, Lee H, Haites EF (eds.)], Cambridge University Press, Cambridge UK, New York USA, pp 367-396

IPCC (2013) Climate Change 2013: The physical science basis. Contribution of Working Group I to the Fifth Assessment Report of the Intergovernmental Panel on Climate Change [Stocker TF, Quin D, Plattner GK, Tignor M, Allen SK, Boschung J, Nauels A, Xia Y, Bex V, Midgley PM (eds.)]. Cambridge University Press, Cambridge UK, New York USA.

IPCC (2014a) Climate Change 2014: impacts, adaptation, and vulnerability. Part A: global and sectoral aspects. Contribution of working group II to the fifth assessment report of the 
intergovernmental panel on climate change. In: Field CB, Barros VR, Dokken DJ, Mach KJ, Mastrandrea MD, Bilir TE, Chatterjee M, Ebi KL, Estrada YO, Genova RC, Girma B, Kissel ES, Levy AN, MacCracken S, Mastrandrea PR, White LL (eds), Cambridge University Press, Cambridge, United Kingdom, New York, NY

IPCC (2014b) Climate change 2014: impacts, adaptation, and vulnerability. In: Barros VR, Field CB, Dokken DJ, Mastrandrea MD, Mach KJ, Bilir TE, Chatterjee M, Ebi KL, Estrada YO, Genova RC, Girma B, Kissel ES, Levy AN, MacCracken S, Mastrandrea PR, White LL (eds) Part B: regional aspects. Contribution of working group II to the fifth assessment report of the intergovernmental panel on climate change. Cambridge University Press, Cambridge, New York

IPCC (2014c) Climate Change 2014: mitigation of climate change. In: Edenhofer O, Pichs-Madruga R, Sokona Y, Farahani E, Kadner S, Seyboth K, Adler A, Baum I, Brunner S, Eickemeier P, Kriemann B, Savolainen J, Schlömer S, von Stechow C, Zwickel T, Minx JC (eds) Contribution of working group III to the fifth assessment report of the intergovernmental panel on climate, Cambridge University Press, Cambridge, New York

IPCC (2018) Global warming of $1.5^{\circ} \mathrm{C}$. An IPCC special report on the impacts of global warming of $1.5^{\circ} \mathrm{C}$ above pre-industrial levels and related global greenhouse gas emission pathways, in the context of strengthening the global response to the threat of climate change, sustainable development, and efforts to eradicate poverty In: Masson-Delmotte V, Zhai P, Pörtner H-O, Roberts D, Skea J, Shukla PR, Pirani A, Moufouma-Okia W, Péan C, Pidcock R, Connors S, Matthews JBR, Chen Y, Zhou X, Gomis MI, Lonnoy E, Maycock T, Tignor M, Waterfield T (eds), In Press

Kirschbaum MUF (2000) Will changes in soil organic carbon act as a positive or negative feedback on global warming? Biogeochemistry 48:21-51

Krey V, Havlik P, Fricko O, Zilliacus J, Gidden M, Struberger M, Kartasamita G, Ermolieva T, Forsell N, Gusti M, Johnson N, Kindermann G, Kolp P, McCollum DL, Pachauri S, Rao S, Rogelj J, Valin H, Obersteiner M, Riahi K (2016) Message-globium 1.0 documentation, international institute for applied system analysis (IIASA), Laxenburg, Austria. https://data.ene.iiasa.ac.at/message-globiom/. Accessed 14 Dec 2019.

Kurane I (2010) The effect of global warming on infectious diseases. Public Health Res Perspect 1:4-9

Latif M, Böning C, Willebrand J, Biastoch A, Dengg J, Keenlyside N, Schewendieck U (2006) Is the thermohaline circulation changing? J Clim 19:4631-4637

Leemans R, Eickhout B (2004) Another reason for concern: regional and global impacts on ecosystems for different levels of climate change. Global Environ Change 14:219-228

Lenton TM (2011) Beyond $2{ }^{\circ} \mathrm{C}$ : redefining dangerous climate change for physical systems. WIREs Clime Change 2:451-461

Lenton TM, Held H, Kriegler E, Hall JW, Lucht W, Rahmstorf S, Schellnhuber HJ (2008) Tipping elements in the Earth's climate system. Proc Natl Acad Sci USA 105:1786-1793

Loarie SR, Duffy PB, Hamilton H, Asner GP, Field CB, Ackerly DD (2009) The velocity of climate change. Nature 462:1052-1057

Lobell DB, Burke MB, Tebaldi C, Mastrandrea MD, Falcon WP, Naylor RL (2008) Prioritizing climate change adaptation needs for food security in 2030. Science 319:607-610

Malcolm JR, Markham A, Neilson RP, Garaci M (2002) Estimated migration rates under scenarios of global climate change. J Biogeogr 29:835-849

Mastrandrea M (2009) Calculating the benefits of climate policy: Examining the assumptions of integrated assessment models, Working Paper, Pew Center on Global Climate Change. Arlington, USA. https://www.environmentportal.in/files/mastrandrea-calculating-benefits-climate-policy-12-22-09. pdf. Accessed 30 Jan 2020.

Mendelsohn R (2000) Efficient adaptation to climate change. Clim Change 45:583-600

Millington R, Cox PM, Moore JR, Yvon-Dorucher G (2019) Modelling ecosystem adaption and dangerous rates of global warming. Emerg Top Life Sci 3:221-231

NASEM (National Academies of Science, Engineering and Medicine) (2017) Valuing climate damages: updating estimation of the social cost of carbon dioxide, The National Academies Press, Washington

Neilson RP (1993) Vegetation Redistribution: A possible biosphere source of $\mathrm{CO}_{2}$ during climate change. Water Air Soil Poll 70:659-673

Neilson RP, Pitelka LF, Solomon AM, Nathan R, Midgley GF, Fragoso JMV, Lischke H, Thompson K (2005) Forecasting regional to global plant migration in response to climate change. Bioscience 9:749-759

Nordhaus WD (1991) To slow or not to slow: the economics of the greenhouse effect. Econ J (R Econ Soc) 101:920-937 
Nordhaus WD (1994) Managing the global commons. The MIT Press, Cambridge

Nordhaus WD (2008) A question of balance-weighing the options of global warming policies. Yale University Press, New Haven, London

Nordhaus WD (2018) Projections and uncertainties about climate change in an era of minimal climate policies. Am Econ J Econ Pol 10:333-360

Nordhaus WD (2019) Climate change: the ultimate challenge for economics. Am Econ Rev 109:1991-2014

Nordhaus WD, Boyer JG (2000) Warming the world: economic models of global warming. The MIT Press, Cambridge

Nordhaus WD, Sztorc P (2013) DICE 2013R: introduction and user's manual. http://www.econ.yale. edu/ nordhaus/homepage/homepage/documents/DICE_Manual_100413r1.pdf. Accessed 30 Jan 2020.

O'Neill BC, Oppenheimer M, Warren R, Hallegatte S, Kopp RE, Pörtner HO, Scholes R, Birkmann J, Foden W, Licker R, Mach KJ, Marbaix P, Mastrandrea MD, Price J, Takahashi K, van Ypersele JP, Yohe G (2017) IPPC reasons for concern regarding climate change risks. Nat Clim Change 7:28-37

Overland JE, Wang M, Walsh JE, Stroeve JC (2013) Future arctic climate changes: adaption and mitigation time scales. Earths Future 2:68-74

Patt AG, van Vuuren DP, Berkhout F, Aaheim A, Hof AF, Isaac M, Mechler R (2010) Adaption in integrated assessment modeling: where do we stand? Clim Change 99:383-402

Peck SC, Teisberg TJ (1994) Optimal carbon emission trajectories when damages depend on the rate or level of global warming. Clim Change 28:289-314

Pedlar JH, McKinney DW, Aubin I, Beardmore T, Beaulieu J, Iverson L O'Neil GA, Winder RS, SteMarie SC (2012) Placing forestry in the assisted migration debate. Bioscience 62:835-842

Petschel-Held G, Schellnhuber HJ, Bruckner T, Toth FL, Hasselmann K (1999) The tolerable window approach: theoretical and methodological foundations. Clim Change 41:303-331

Pindyck RS (2013) Climate change policy: what do the models tell us? J Econ Lit 51:860-872

Pindyck RS (2017) The use and misuse of models for climate policy. Rev Environ Econ Policy 11:110-114

Price DT, Alfaro RI, Brown KJ, Flannigan MD, Fleming RA, Hogg EH, Girardin MP, Lakusta T, Johnston M, McKenney DW, Pedlar JH, Stratton T, Sturrock RN, Thompson ID, Trofymow JA, Venier LA (2013) Anticipating the consequences of climate change for Canada's boreal forest ecosystems. Environ Rev 21:322-365

Rickards L, Howden SM (2012) Transformational adaption: agriculture and climate change. Crop Pasture Sci 63:240-250

Rogelj J, den Elzen M, Höhne N, Fransen T, Fekete H, Winkler H, Schaeffer R, Sha F, Riahi K, Meinshausen M (2016) Paris agreement climate proposals need a boost to keep warming well below 2 ${ }^{\circ} \mathrm{C}$. Nature 762:631-639

Romer PM (1990) Endogenous technological change. J Pol Econ 98:71-102

Shayegh S, Moreno-Cruz J, Caldeira K (2016) Adapting to rates versus amounts of climate change: a case of adaption to sea-level rise. Environ Res Lett 11:104007

Stanton EA, Ackerman F (2009) Climate and development economics: balancing science, politics and equity. Nat Resour Forum 33:262-273

Stanton EA, Ackerman F, Kartha S (2009) Inside the integrated assessment models: Four issues in climate economics. Clim Dev 1:166-184

Stehfest E, van Vuuren D, Kram T, Bouwman L, Alkemade R, Bakkenes M, Biemans H, Bouwman A, den Elzen M, Janse J, Lucas P, van Minnen J, Müller M, Prins A (2014) Integrated assessment of global environmental change with IMAGE 3.0. Model description and policy applications. PBL Netherlands Environmental Agency, The Hague

Stern N (2007) The economics of climate change-the Stern review. Cambridge University Press, Cambridge

Stern N (2013) The structure of economic modeling of the potential impacts of climate change: grafting gross underestimation of risk onto already narrow science models. J Econ Lit 51:838-859

Tahvonen O (1995) Dynamics of pollution control when damage is sensitive to the rate of pollution accumulation. Enviro and Resour Econ 5:9-27

Tambo JA, Aboulaye T (2012) Climate change and agricultural technology adoption: the case of drought tolerant maize in rural Nigeria. Mitig Adapt Strat Glob Change 17:277-292

Tambo JA, Aboulaye T (2013) Smallholder farmers' perceptions of and adaptations to climate change in the Nigerian savanna. Reg Environ Change 13:375-388 
Tol RSJ (1997) On the optimal control of carbon dioxide emissions: an application of FUND. Environ Model Assess 2:151-163

Tol RSJ, Anthoff D (2014) The climate Framework for Uncertainty, Negotiation and Distribution (FUND), technical description, version 3.9. https://www.fund-model.org/files/docu-mentation/ Fund-3-9-Scientific-Documentation.pdf. Accessed 14 Dec 2019.

Toth FL, Bruckner T, Füssel HM, Leimbach M, Petschel-Held G (2003) Integrated assessment of longterm climate policies: part 2-model results and uncertainty analysis. Clim Change 56:57-72

van Vliet A, Leemans R (2006) Rapid species" responses to changes in climate require stringent climate protection targets. In: Schellnhuber HJ, Cramer W, Nakicenovic N, Wigley T, Yohe G (eds) Avoiding dangerous climate change. Cambridge University Press, Cambridge, pp 135-141

van Vuuren DP, Lowe J, Stehfest E, Gohar L, Hof AF, Hope C, Warren R, Meinshausen M, Plattner GK (2011a) How well do integrated assessment models simulate climate change? Clim Change 104:255-285

Vuuren DP, van Edmonds J, Kainuma MLT, Riahi K, Thomson A, Matsui T, Hurtt G, Lamarque JF, Meinshausen M, Smith S, Grainer C, Rose S, Hibbard KA, Nakicenovic N, Krey V, Kram TT (2011b) The representative concentration pathways: an overview Clim Change 109531

Vellinga P, Swart R (1991) The greenhouse marathon: a proposal for a global strategy. Clim Change 18:7-12

Visser ME (2008) Keeping up with a warming world; assessing the rate of adaptation to climate change. Proc R Soc Lond B 275:649-659

Warren R, Price J, Fischlin A, de la Nava SS, Midgley G (2011) Increasing impacts of climate change upon ecosystems with increasing global mean temperature rise. Clim Change 106:141-177

Weitzman ML (2011) Fat-tailed uncertainty in the economics of catastrophic climate change. Rev Environ Econ Policy 5:275-292

Weyant J (2017) Some contributions of integrated assessment models of global climate change. Rev Environ Econ Policy 11:115-137

Wilson C, Kriegler E, van Vuuren DP, Guivarch C, Frame D, Krey V, Osborn TJ, Schwanitz VJ, Thompson EL (2017) Evaluating process based integrated assessment models of climate change mitigation. Working Paper WP-17-007, International Institute for Applied Systems Analysis (IIASA), Laxenburg, Austria. https://pure.iiasa.ac.at/id/eprint/14502/1/WP-17-007.pdf. accessed 30 Jan 2020.

Wirths H, Rathmann J, Michaelis P (2018) The permafrost carbon feedback in DICE-2013R: modeling and empirical results. Environ Econ Policy Stud 20:109-124

Zhang W, Ricketts TH, Kremen C, Carney K, Swinton SM (2007) Ecosystem services and dis-services to agriculture. Ecol Econ 64:253-260

Zhu K, Woodall CW, Clark JS (2012) Failure to migrate: lack of tree range expansion in response to climate change. Global Change Biol 18:1042-1052

Zickfeld K, Knopf B, Petoukhov V, Schellnhuberl HJ (2005) Is the Indian summer monsoon stable against global change? Geophys Res Lett 32:L15707

Publisher's Note Springer Nature remains neutral with regard to jurisdictional claims in published maps and institutional affiliations. 